Review Article

Human and Medical Genetics

\title{
Beyond the HLA polymorphism: A complex pattern of genetic susceptibility to pemphigus
}

\author{
Maria Luiza Petzl-Erler ${ }^{1}$ iD \\ ${ }^{1}$ Universidade Federal do Paraná, Departamento de Genética, Laboratório de Genética Molecular Humana, \\ Curitiba, PR, Brazil.
}

\begin{abstract}
Pemphigus is a group of autoimmune bullous skin diseases that result in significant morbidity. As for other multifactorial autoimmune disorders, environmental factors may trigger the disease in genetically susceptible individuals. The goals of this review are to summarize the state of knowledge about the genetic variation that may affect the susceptibility and pathogenesis of pemphigus vulgaris and pemphigus foliaceus - both the endemic and the sporadic forms -, to compare and discuss the possible meaning of the associations reported, and to propose recommendations for new research initiatives. Understanding how genetic variants translate into pathogenic mechanisms and phenotypes remains a mystery for most of the polymorphisms that contribute to disease susceptibility. However, genetic studies provide a strong foundation for further developments in this field by generating testable hypotheses. Currently, results still have limited influence on disease prevention and prognosis, drug development, and clinical practice, although the perspectives for future applications for the benefit of patients are encouraging. Recommendations for the continued advancement of our understanding as to the impact of genetic variation on pemphigus include these partially overlapping goals: (1) Querying the functional effect of genetic variants on the regulation of gene expression through their impact on the nucleotide sequence of cis regulatory DNA elements such as promoters and enhancers, the splicing of RNA, the structure of regulatory RNAs and proteins, binding of these regulatory molecules to regulatory DNA elements, and alteration of epigenetic marks; (2) identifying key cell types and cell states that are implicated in pemphigus pathogenesis and explore their functional genomes; (3) integrating structural and functional genomics data; (4) performing disease-progression longitudinal studies to disclose the causal relationships between genetic and epigenetic variation and intermediate disease phenotypes; (5) understanding the influence of genetic and epigenetic variation in the response to treatment and the severity of the disease; (6) exploring gene-gene and genotype-environment interactions; (7) developing improved pemphigus-prone and non-prone animal models that are appropriate for research about the mechanisms that link genotypes to pemphigus. Achieving these goals will demand larger samples of patients and controls and multisite collaborations.
\end{abstract}

Keywords: Pemphigus foliaceus, pemphigus vulgaris, blistering skin diseases, autoimmunity, genetic susceptibility.

Received: October 31, 2019; Accepted: April 6, 2020.

\section{Introduction}

Pemphigus is a group of autoimmune skin diseases of unclear etiology, characterized by epidermal blisters and erosions in the stratified squamous epithelium affecting the skin and/or mucous membranes. The main forms are pemphigus vulgaris (PV) and pemphigus foliaceus (PF). Pemphigus patients produce immunoglobulin $\mathrm{G}(\mathrm{IgG})$ antibodies targeting proteins at the cell surface of keratinocytes. The autoantigens are part of the desmosomes, the molecular complexes specialized for cell-to-cell adhesion by anchoring intermediate filaments. Keratinocytes within pemphigus lesions lose cell-cell adhesion due to damage of desmosomes, a process named acantholysis. While PV can affect either the mucous membranes alone or the mucous membranes and the skin, in PF lesions develop only in the skin. The primary autoantigens are desmoglein 1 (DSG1) in PF and desmo-

Send correspondence to Maria Luiza Petzl-Erler. Universidade Federal do Paraná, Departamento de Genética, Laboratório de Genética Molecular Humana, 81531-980, Curitiba, PR, Brazil. E-mail: perler@ufpr.br. glein 3 (DSG3) in PV, but PV patients may also develop anti-DSG1 autoantibodies. Detection of anti-desmoglein antibodies in patients with pemphigus is a hallmark and a diagnostic criterion. Additional autoantigens have been identified in PV patients (Kalantari-Dehaghi et al., 2013; Sajda et al., 2016); however, the significance of the non-desmoglein targets is unknown.

Diagnosis is based on clinical, histological, and immunochemical criteria. If untreated, pemphigus has a poor prognosis, and mortality is high, especially for PV. Treatment is primarily by systemic corticosteroids, and adjuvant broadscale immunosuppression, whose side effects can be severe. Other adjuvant therapies for patients with high levels of circulating autoantibodies are high-dose intravenous immunoglobulin (IVIg) and plasmapheresis or extracorporeal immunoadsorption with protein $\mathrm{A}$. A promising option is the depletion of B lymphocytes with rituximab, a monoclonal antibody targeting CD20+ B cells, particularly in the treatment of patients who develop serious side effects or do not respond to conventional therapy. Some emerging therapies that have shown pos- 
itive outcomes in other autoimmune diseases are being investigated (Ruocco et al., 2013; Kasperkiewicz et al., 2017; Hans-Filho et al., 2018; Yanovsky et al., 2019).

Pemphigus frequency varies according to geographic area and ethnic groups (Alpsoy et al., 2015). Both PF and PV are rare, but, in most of the world, PV is more frequent, corresponding to $65 \%-85 \%$ of the pemphigus cases. The mean incidence of PV usually is higher in women, but the female:male ratio varies among populations from 0.45 to 5 . The incidence reported for the different regions of Europe ranged between 0.5 and 2.4 per million and year. In Southern and Eastern Europe, the frequency of the disease is higher than in North and Central Europe; in Turkey, the yearly incidence was reported as 2.4 per million. The incidence in Asia varied between 1.6 and 16.1 per million. In North America, the incidence was reported as 32 per million in people of Jewish origin and 4.2 per million for people on non-Jewish ancestry. In Africa, the yearly incidence of pemphigus was reported as 2.9 per million in Mali and 6.7 and 8.6 per million in Tunisia. Most of these figures refer to pemphigus in general, or to only PV.

As for PF, it is generally even rarer than PV, but PF reaches high frequency in regions of endemicity in South America and Tunisia. The highest incidence of PF occurs in central-western Brazil, where the disease is known as fogo selvagem (FS, meaning wild fire in Portuguese). The incidence varies among regions and time from 9 to 83 cases per million inhabitants per year and the female:male ratio is approximately 1.5. Endemic foci have also been reported for Colombia, Venezuela, Peru, Bolivia, Argentina and Paraguay (Chiossi and Roselino, 2001). The highest prevalence has been observed in the Xavante and Terena Amerindians (1.4\% and more than 3\%, respectively; Aoki et al., 2004). In central and southern Tunisia, the yearly incidence of pemphigus was estimated at 6.7 cases per million and year, of which $61 \%$ were PF, particularly women living in rural areas, with a female:male ratio of 4.1 (Bastuji-Garin et al., 1995). However, in the north of the country, the incidence was of 8.6 cases per million and $61 \%$ were PV patients with a female:male ratio of 2 (Zaraa et al., 2011).

The mechanism resulting in the breakdown of the immunological tolerance remains unknown. However, it seems settled that the onset and the course of pemphigus depend on environmental factors triggering the disease in individuals with a predisposing genetic background (Figure 1). Although essential, the complex genetic background does not suffice for disease outbreak; exposure to ill-defined precipitating environmental factors is required. These also may differ between subjects and are related to their lifestyle. Many factors have been associated with the onset or the course of pemphigus. Certain drugs may interfere with the keratinocyte membrane biochemistry and/or with the immune balance (respectively, biochemical and immunologic acantholysis). Viral infections, primarily the herpetic ones, may trigger the outbreak of pemphigus or complicate its clinical course. The precipitating effect of the viral attack may result from overactivated inflammatory and immune responses. Rare, but well-documented events that may trigger the disease in susceptible individuals are physical agents (ultraviolet or ionizing radiation, thermal or electrical burns, surgery and cosmetic procedures), contact allergens (e.g., organophosphate pesticides), dietary factors (e.g., garlic, leek, onion, black pepper, red chili pepper, red wine, tea), and emotional stress (Ruocco et al., 2013). Epidemiological features of FS in Brazil indicate continued exposure to certain hematophagous insect bites as a possible precipitating factor of the disease (Lombardi et al., 1992; Aoki et al., 2004; Qian et al., 2016).

Herein I provide a comprehensive overview of the genetic risk factors and discuss insights into pemphigus pathogenesis that this knowledge is revealing. Both pemphigus foliaceus and pemphigus vulgaris are addressed. Associations are discussed considering the function of the gene product, the allele or haplotype frequencies in populations, the strength and statistical significance of the association, sample size, and statistical power.

\section{Pemphigus genetics}

\section{Evidence for a genetic basis}

Although no systematic study of pemphigus recurrence in families has been published, several reports underscore the influence of a polygenic genetic background in susceptibility and pathogenesis.

Among first-degree relatives of PV patients only two cases $(0.24 \%)$ of PV were seen among 830 first-degree relatives of PV patients, and none among relatives of 890 controls, while the prevalence of any autoimmune disease (AD) was $7.4 \%$ in relatives of the patients compared to $2.3 \%$ in relatives of the controls (Firooz et al., 1994). In a survey of $171 \mathrm{PV}$ patients, the prevalence of AD among first-, secondand third-degree relatives of patients was $50.6 \%$, and $34.3 \%$ and $15.1 \%$, respectively (Gupta et al., 2011), in agreement with partially shared genetic and environmental factors between AD.

In one Terena Amerindian population in Brazil with a prevalence of FS close to $3 \%$, over half of the patients (16 of 29) had at least one relative (parent, sibling, aunt/uncle, cousin) with the disease (Hans-Filho et al., 1999). Unfortunately, the prevalence among matched relatives of nondiseased individuals in that population was not reported.

The wide range of incidence among populations around the globe is often interpreted as evidence for a genetic basis of multifactorial diseases such as pemphigus, however (differently from monogenic disease), variable exposure to triggering non-genetic factors is a likely cause of this heterogeneity. The alternative hypotheses should be better explored in future studies.

Nonetheless, the associations with multiple genetic variants thus far described support the hypothesis that pemphigus are complex multifactorial diseases. Susceptibility is clearly polygenic, meaning that specific genotypes at multiple loci are involved. As is the case for other complex disorders, the involved polygenes overlap only partially between 


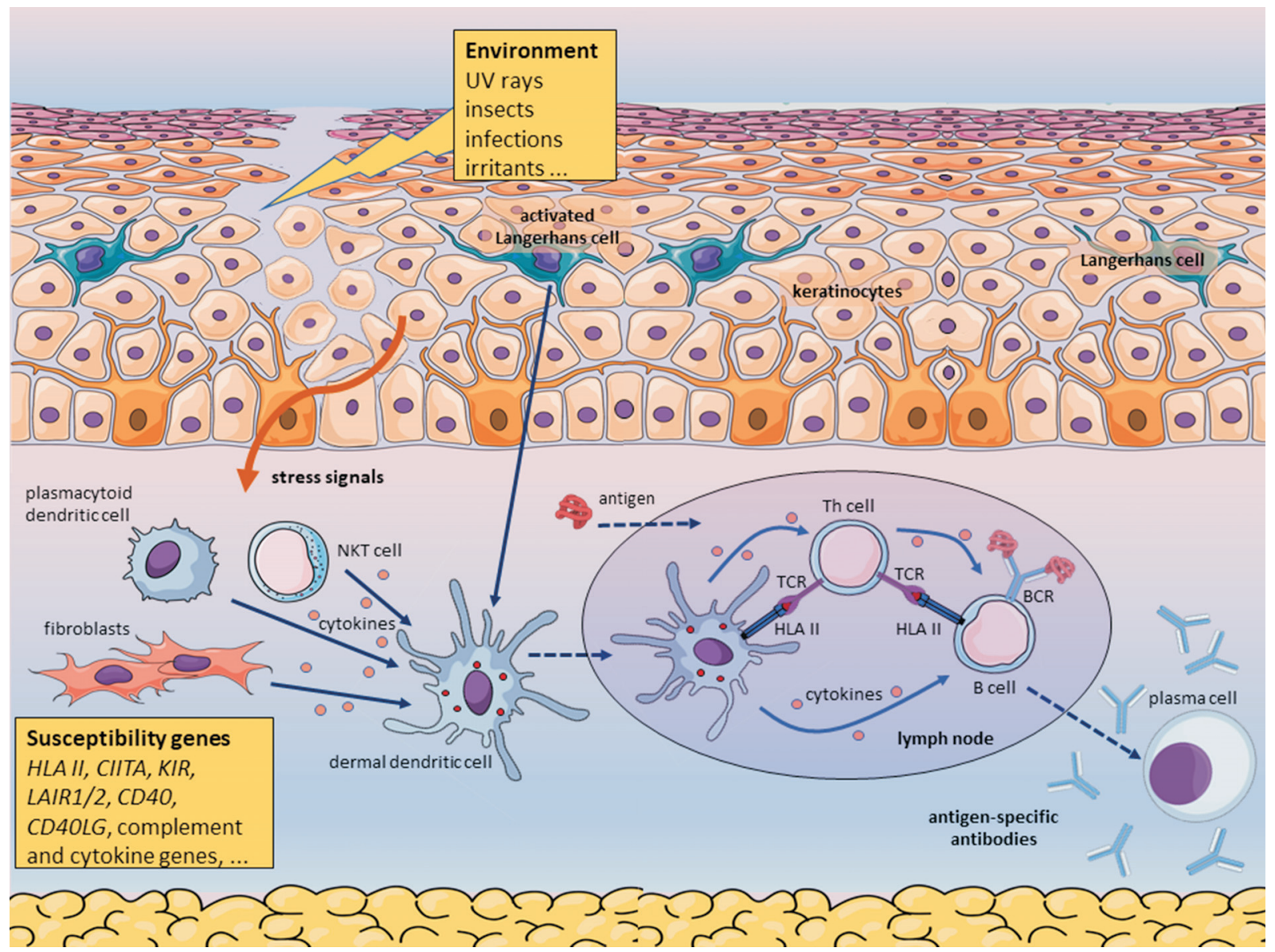

Figure 1 - Environmental factors trigger pemphigus in genetically predisposed individuals carrying susceptibility genotypes. According to this hypothetical mechanism, insect saliva, virus, or other environmental factor triggers mast cell degranulation, which increases the permeability of blood vessels, causing edema. Langerhans cells and keratinocytes react to the noxious environmental stimulus producing pro-inflammatory cytokines and delivering other stress signals. Skin-resident innate immune cells and fibroblasts may contribute to the local inflammatory response. Inflammation leads to the recruitment of neutrophils and monocytes. The first encountered antigen derived from the environmental triggering factor is yet unknown. Activated antigen-presenting cells (APC) such as dermal dendritic cells process proteins derived from the environmental agent, migrate to skin-draining lymph nodes and present antigenic peptides bound to HLA class II molecules to T cells. In the secondary lymphoid organ, the Thelper cells activate B cells primed by the same antigen. This model predicts that $\mathrm{T}$ cells specific for an environmental peptide bound to a susceptibility HLA class II molecule cross-reacts with a self-peptide bound to the same type of HLA molecule, such that peptides derived from a non-self protein mimic peptides of the self-protein desmoglein when bound to the relevant HLA protein. Similarly, the disease may be triggered in the intestine and perhaps other tissues by an environmental or microbiota-derived antigen.

patients and none of the variants conferring genetic susceptibility is essential or sufficient for disease manifestation.

Variants of numerous genes have been analyzed, especially in FS, almost always in case-control association studies. Most candidates were genes whose products are involved in immune responses, in line with the autoimmune and autoinflammatory features of pemphigus. Data for PV and PF exist for populations of Europe, South and North America, East Asia, the Middle East, and North Africa and are described below and summarized in Table 1, and Tables S1 and S2.

\section{HLA and other major histocompatibility complex $(\mathrm{MHC})$ genes}

\section{Classical HLA genes}

As for most ADs, for pemphigus associations with the classical HLA class II genes were also the first described and their variants are the strongest determinants of disease risk.
Since the mid-1970s, numerous studies addressed a possible effect of HLA alleles on PV and PF pathogenesis. Pioneering studies used low-resolution serology to genotype HLA class I antigens only. Soon after the development of medium- to high-resolution typing at the DNA level in the 1980 s, it was thought that the "true" associations with individual alleles would be discovered, facilitating understanding of the mechanisms governing susceptibility/resistance to pemphigus and other HLA associated diseases. However, since then, the enhanced insight into protein structure vs. function revealed additional layers of complexity.

The mechanisms by which some HLA alleles may impact the development of ADs are not precisely known, but it is reasonable to suppose that they are related to structural and functional aspects of peptide binding and interaction with the cognate receptors. Like most proteins, the HLA molecules also have pleiotropic effects, as illustrated by the func- 
Petzl-Erler

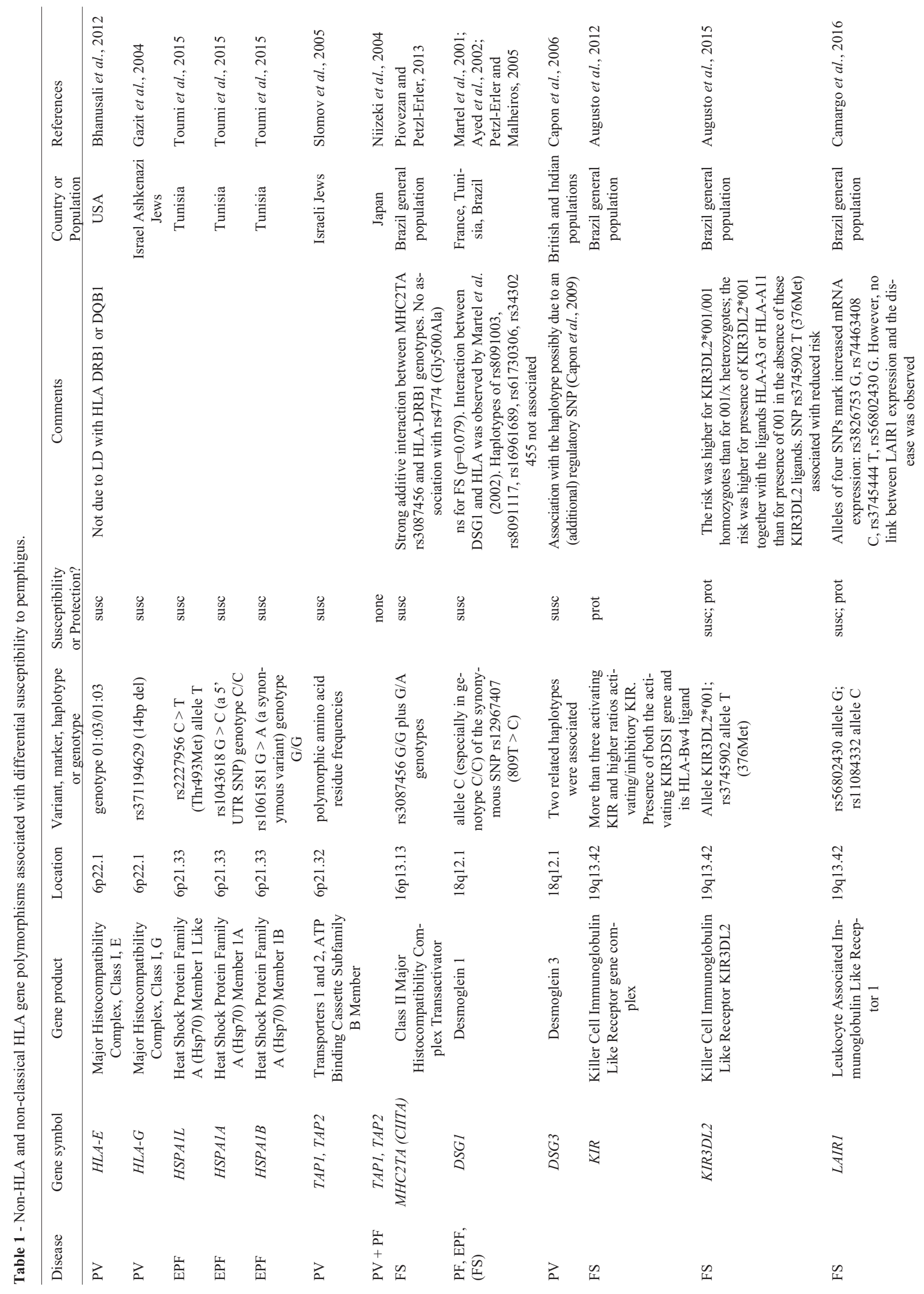


I In

IIII
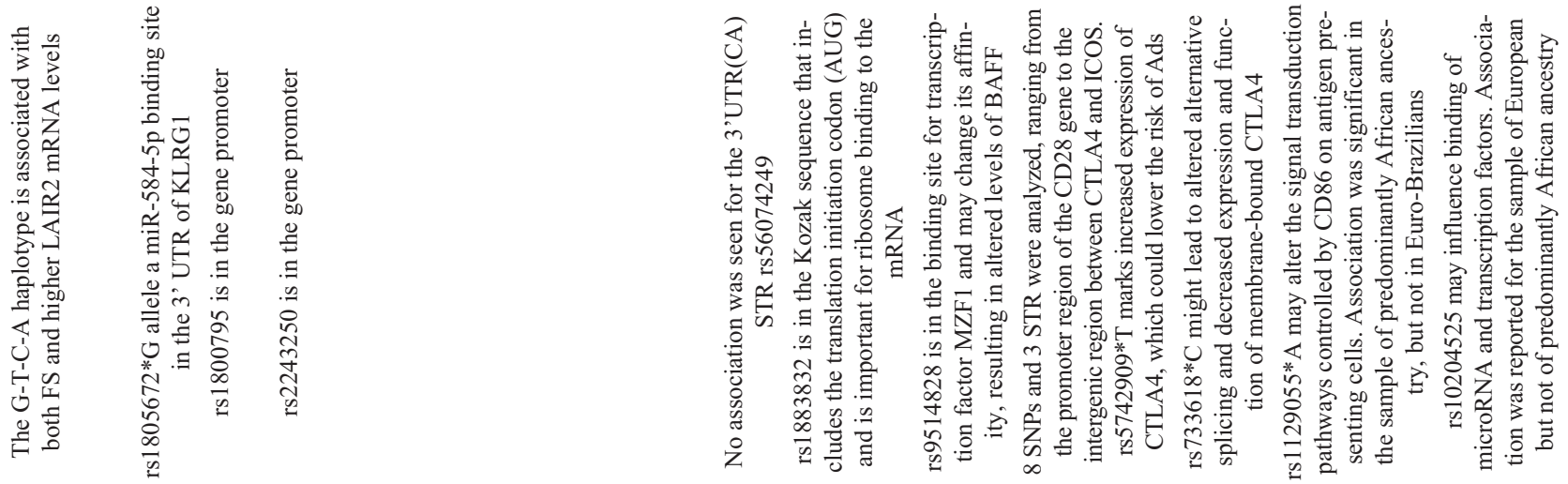

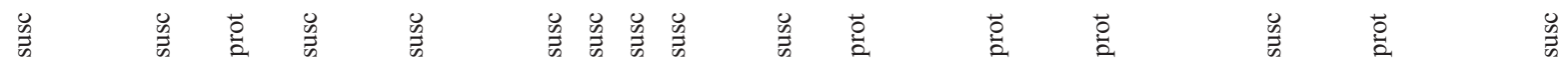

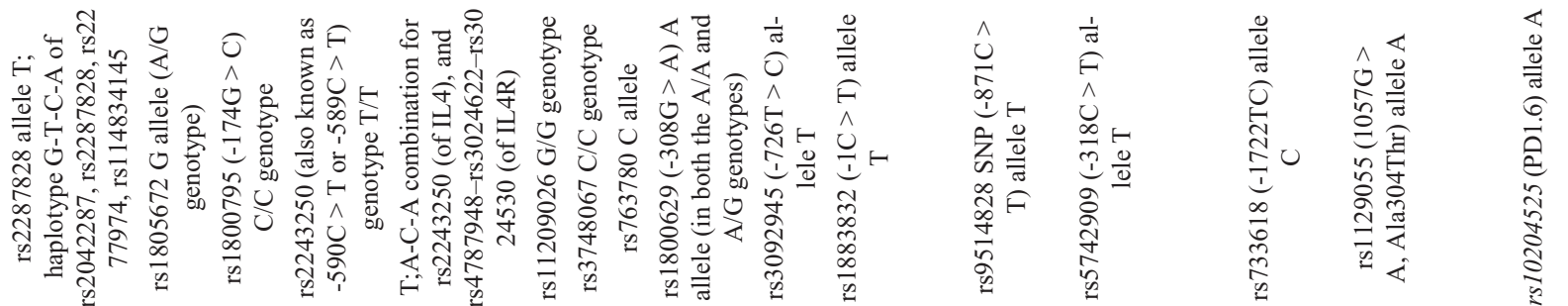

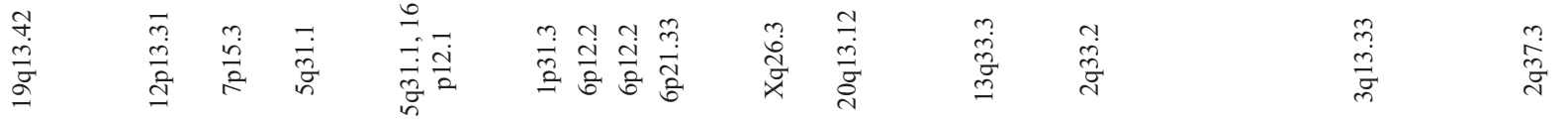

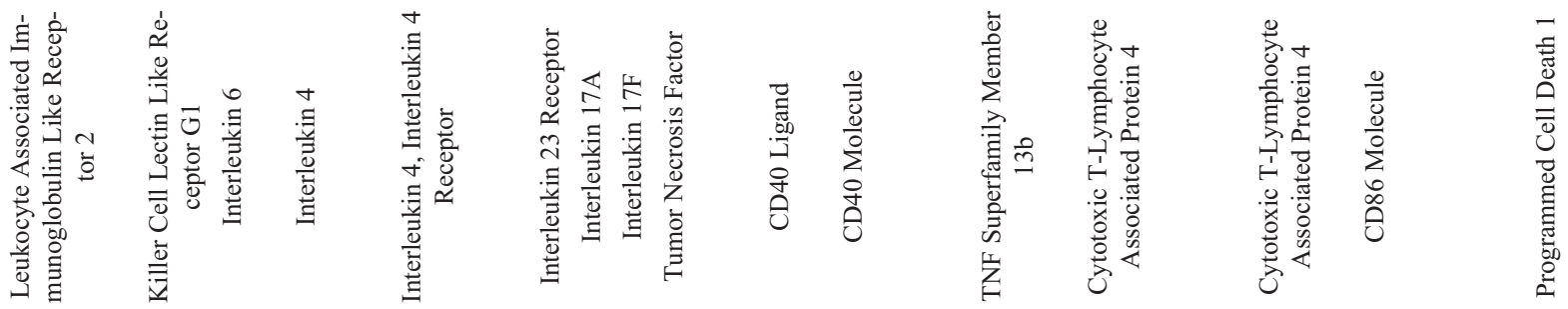

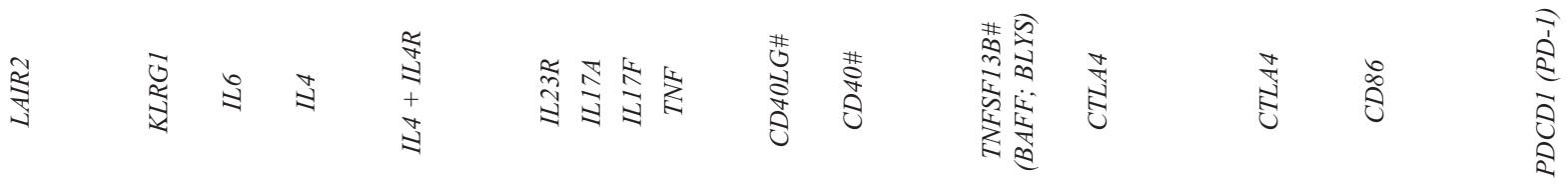

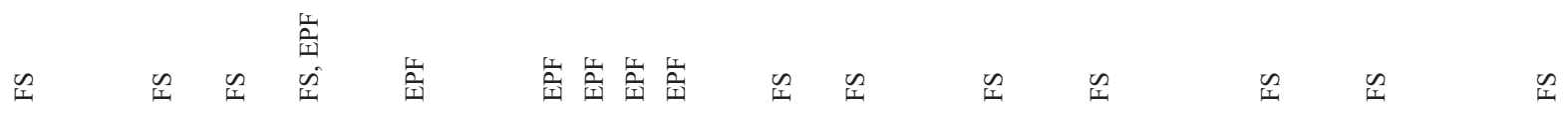




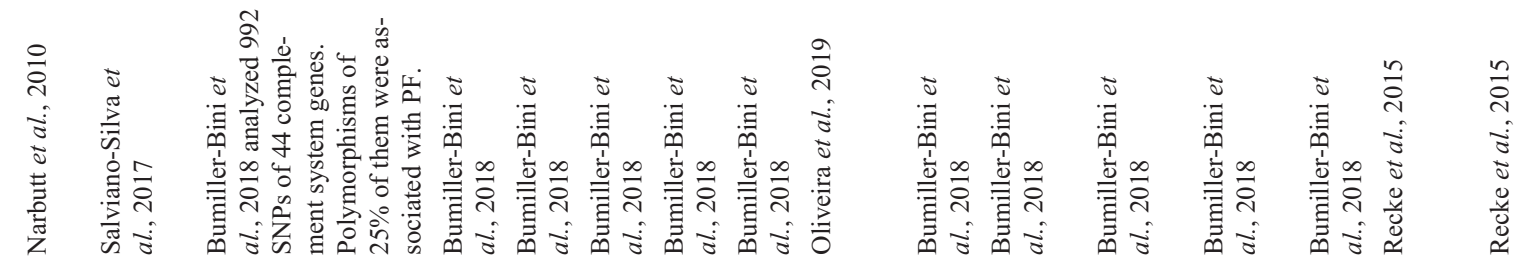

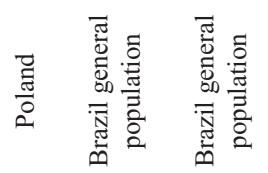

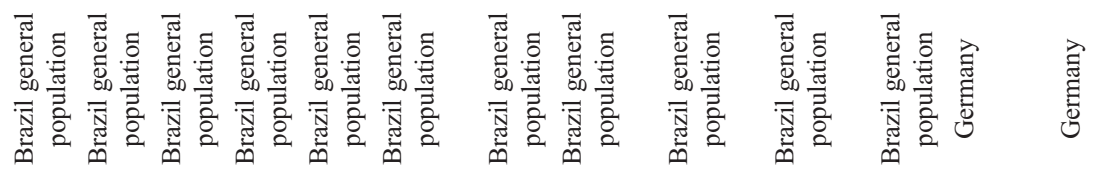
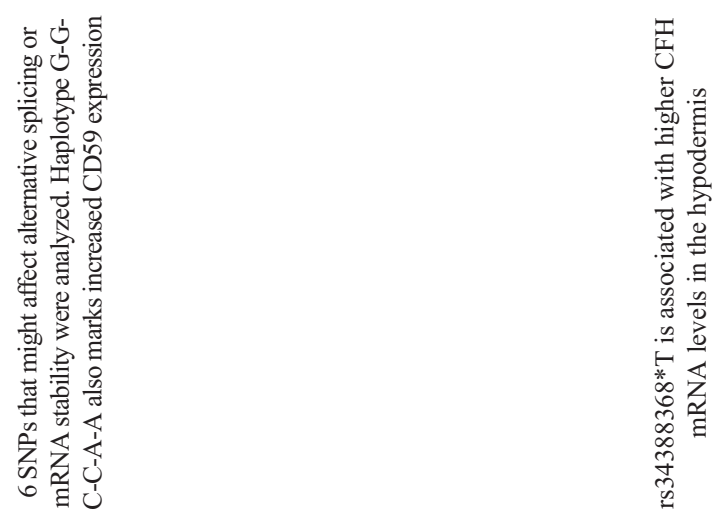

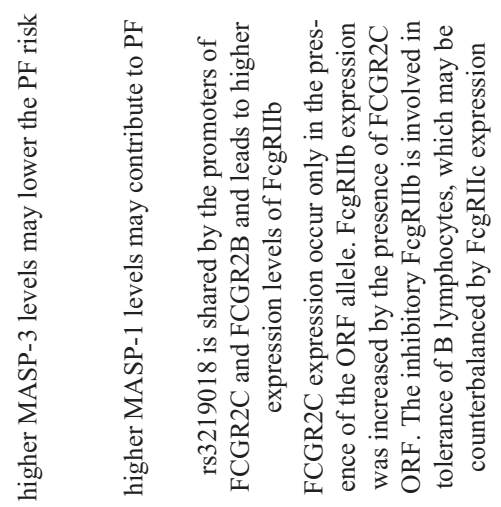

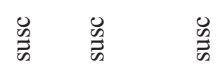

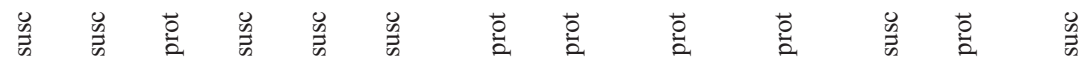
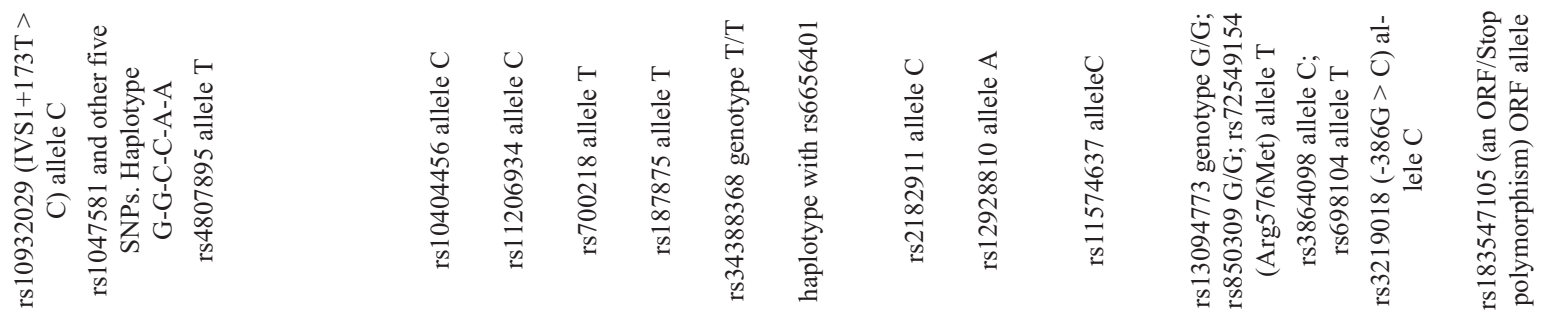

तु) $\stackrel{m}{\stackrel{n}{a}} \stackrel{m}{=}$

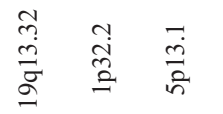

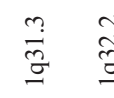

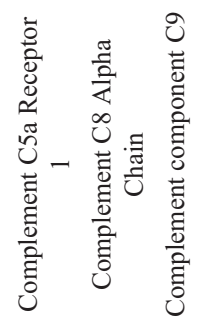

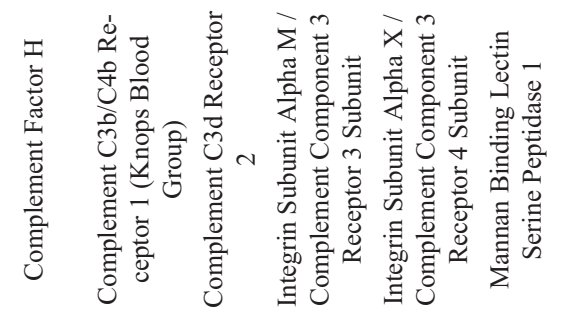

高量

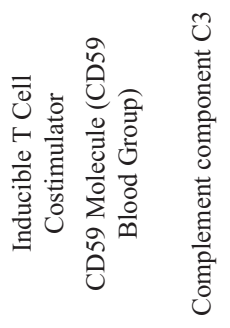

₹

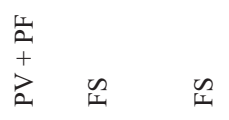

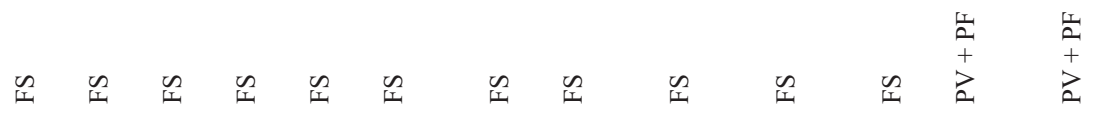




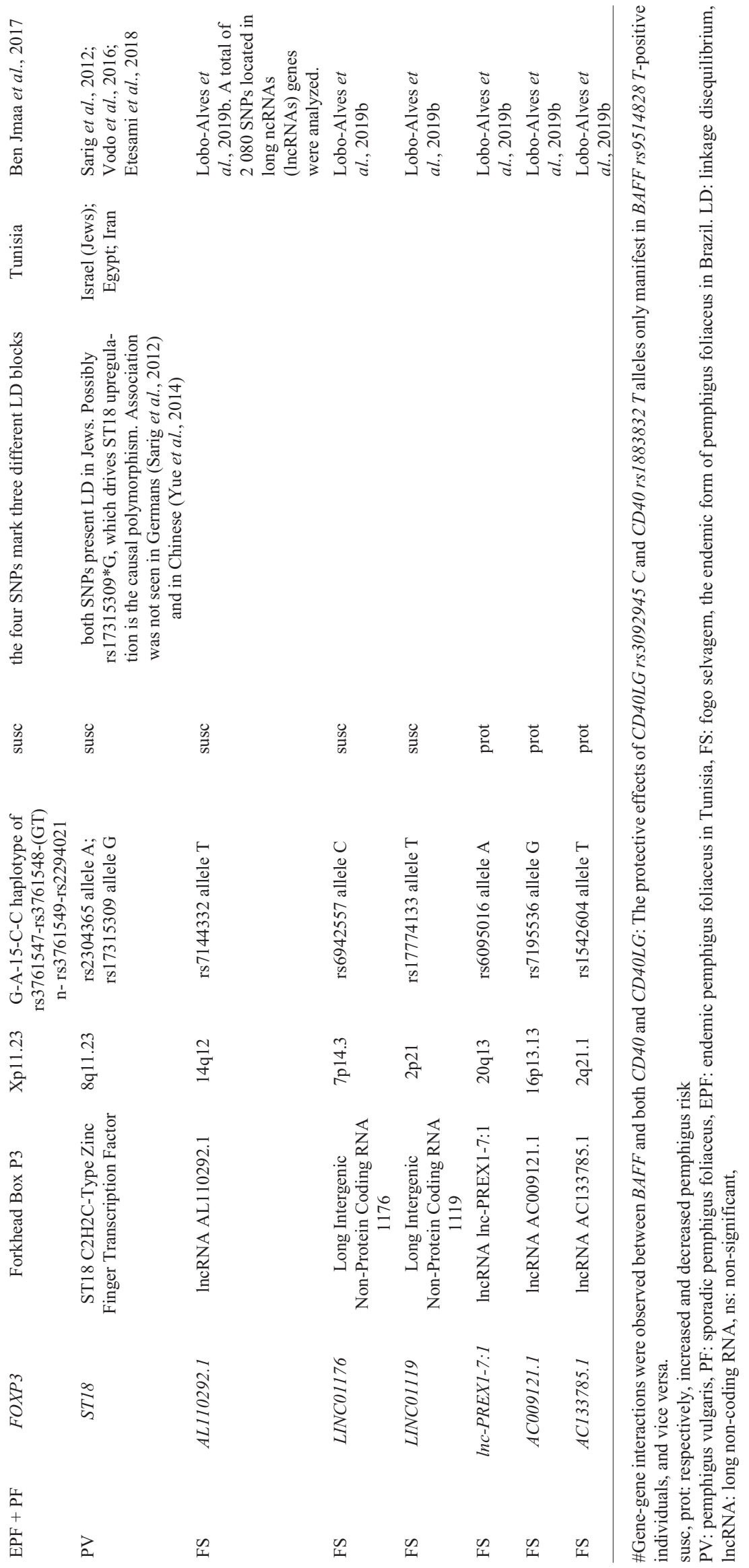


tions of HLA class I molecules as ligands for both the T lymphocyte receptors and NK cell receptors. Very different polymorphic motifs of the HLA and their receptor molecules impact these two interactions. Also, the expression levels may differ between alleles of the same HLA locus, with functional consequences. Therefore, the genetic associations with diseases shall be further investigated, considering that functional complexity.

On the other hand, there are some characteristics of HLA that hinder a clear conclusion about the causal susceptibility and protective HLA class II alleles in pemphigus as well as other diseases: (a) linkage disequilibrium (LD) between the analyzed genes, as will be discussed below; (b) additive or epistatic functional interactions between HLA$D R B 1, D Q A 1$ and $D Q B 1$, meaning that the haplotype rather than the individual alleles correspond to the disease-relevant genetic unit. The same rationale can be extended to the HLA genotype (union of the two HLA haplotypes of any individual) and other not investigated MHC genes; (c) the multiple HLA-DQ molecules in double heterozygous individuals: the HLA-DQ heterodimer can be formed by the alpha and beta chains encoded in cis, i.e., by $H L A-D Q A 1$ and $-D Q B 1$ genes of the same haplotype, or in trans, the corresponding genes of the paternal plus the maternal haplotype.

In most studies, only the $H L A-D R B 1$ and $H L A-D Q B 1$ class II genes were analyzed, but several also analyzed $H L A-D Q A 1$; a few searched for associations with the classical class I (Ia) genes $H L A-A, H L A-B$ or $H L A-C$. Even less looked at non-classical HLA class I genes (Ib) and non-HLA MHC genes.

Regarding the class Ia genes, associations differ greatly between populations, while this is less evident for the class II genes. Probably the majority of the class Ia associations result from LD with $H L A-D R B 1$ and $H L A-D Q B 1$ alleles, but a direct effect cannot be ruled out. Indeed, associations between PF and the HLA Ia ligands of KIR have been detected (Augusto et al., 2012, 2015) and will be presented in this review together with KIR associations.

While PF and PV share several susceptibility and protective HLA variants, significant differences point to partially dissimilar etiology and pathogenesis of these diseases. Conversely, differences among populations for the same pemphigus form are mostly due to the different frequencies of the alleles and haplotypes, but some may have a biological basis, possibly related to environmental triggering factors and the immune response to specific peptides. The observed associations are described below. A summary of the associations between pemphigus and HLA class II alleles and haplotypes is presented in Tables S1 and S2.

Much work has been dedicated to the search of associations between $H L A$ alleles of the classical class II genes and haplotypes in pemphigus vulgaris. Ashkenazy Jewish patients with PV presented significantly higher frequencies of $H L A-D R 4-H L A-D Q w 8(3)$ haplotypes than the matched control group (Ahmed et al., 1990). The results of case-control association studies of European, Western and Southern Asian, and North and South American populations of Euro- pean and Western Asian ancestry showed that the risk haplotype is $D R B 1 * 04: 02-D Q A 1 * 03: 01-D Q B 1 * 03: 02$ (Table $\mathrm{S} 1)$. Apart from the data presented in the PV studies, this conclusion is based on the frequency of the individual alleles and this haplotype in the populations studied, available at Allele Frequencies Net Database (AFND; Gonzalez-Galarza et al., 2018). Allele DRB1*04:06 in the Japanese and Chinese is a PV susceptibility allele as well (Yamashina et al., 1998; Zhang et al., 2019). In the DRB1*04 haplotypes, the association with $D Q A 1 * 03: 01-D Q B 1 * 03: 02$ seems secondary to the association with $D R B 1 * 04$, as a result of high linkage disequilibrium (LD): The alleles $D R B 1 * 04: 01,04: 03$ and 04:05 (and other) also are inserted in $D Q A 1 * 03: 01-D Q B 1 * 03: 02$ haplotypes, but were not associated with increased susceptibility to PV (e.g., Carcassi et al., 1999; Haase et al., 2015). In fact, DRB1*04:01 may be a protective allele in the German population (Haase et al., 2015).

Another haplotype commonly associated with increased PV risk is DRB1*14:54(14:01)-DQA1*01:04$D Q B 1 * 05: 03$ (or $D Q B 1 * 05: 02$ in Iran and Japan) (Table $\mathrm{S} 1)$. Before its description, allele $D R B 1 * 14: 54$ was routinely typed as $D R B 1 * 14: 01$. Resolving the $D R B 1 * 14: 54 / 14: 01$ ambiguity showed high relative ratios of $D R B 1 * 14: 54$ $(87-94 \%)$ in north to central Europe, contrasting with lower ratios (47-76\%) in south and east Europe (Vidan-Jeras et al., 2014). In East Asia, all individuals previously typed as $D R B 1 * 14: 01$ were $D R B 1 * 14: 54$ and $D Q B 1 * 05: 02$ or $05: 03$ (Lee and Jung, 2009; He et al., 2012). The functional impact of this difference - that is limited to one amino acid replacement at position 112 - may not be relevant for $H L A-D R B 1$ biological function. Other $D R B 1 * 14$ alleles also are associated with PV risk: In European and Euro-descendant populations, $\quad D R B 1 * 14: 04$ and *14:05, which occur in $D Q B 1 * 05: 03$ haplotypes (Table $\mathrm{S} 1$ ). In Indo-Asians $D R B 1 * 14: 04$ also is associated with PV (Saha et al., 2010). In Japanese, the haplotypes $D R B 1 * 14: 54(14: 01)$ or 14:05$D Q A 1 * 01: 04-D Q B 1 * 05: 03$ were associated with PV (Yamashina et al., 1998). In Chinese, DRB1*14:04, 14:05, and 14:54 were common among PV patients, as well as $D Q A 1 * 01: 01$ and $D Q B 1 * 05: 03$ (Sun et al., 2019; Zhang et al., 2019); however, haplotype analysis was not performed for that population. In fact, all the $D R B 1 * 14$ alleles that are common in one or the other of the populations studied (references in Table S1 and Gonzalez-Galarza et al., 2018) were associated with increased PV risk. Differences between populations are mostly explained by the allele frequencies and/or low statistical power. It has been suggested that the disease-relevant allele of the $D R B 1 * 14: 54(14: 01)$ haplotype is $D Q B 1 * 05: 03$ alone (Lee et al., 2009), but the PV risk haplotype $D R B 1 * 14: 54 / 14: 01-D Q B 1 * 05: 02$ haplotype (Yamashina et al., 1998; Shams et al., 2009) challenges this interpretation. Conversely, allele $D Q B 1 * 05: 02$ also occurs in the non-susceptibility $D R B 1 * 15$ and $D R B 1 * 16$-bearing haplotypes (Párnická et al., 2013; Zivanovic et al., 2016) and cannot be a causal susceptible or protective allele.

Moreover, the allele $D R B 1 * 08: 04$ is associated with PV in Brazilian and Egyptian (DRB1*08:04-DQA1*05:01- 
$D Q B 1 * 03: 01$ ), and Italian (possibly DRB1*08:04$D Q A 1 * 04: 01-D Q B 1 * 04: 02)$ populations. The 3-loci haplotypes were inferred here based on the PV-associations (Table S1) and worldwide frequencies available at AFND (Gonzalez-Galarza et al., 2018).

Several of the studies do not report protective alleles and haplotypes or mention only the allele groups. The available data indicate that all major $H L A-D R B 1$ allele groups apart from $D R B 1 * 04,08$ and 14 present lower frequency among PV patients compared to controls: $D R B 1^{*} 03,07,11$, 13 and 15 in six to eleven of the populations $D R B 1 * 01$ in three, $D R B 1 * 16$ in two, and $D R B 1 * 09$ in one (Table S1). This difference between associations of PV with $D R B 1$ alleles is mostly due to low allele frequency in the populations studied. For example, the frequency of $D R B 1^{*} 09$ is of 0 to $2 \%$ in the populations with exception of Chinese and Japanese $(12 \%-16 \%)$. For HLA-DQB1, alleles DQB1*02, *06 and $* 03: 01$ are markers of decreased risk (Table S1). The LD pattern indicates that HLA-DQB1 rather than HLA-DRB1 alleles may be the relevant protective factors: Worldwide, $D Q B 1 * 02$ occurs almost exclusively together with $D R B 1 * 03: 01$ or 07:01 whose frequency is decreased among patients. However, $D R B 1^{*} 07: 01$ may also occur with $D Q B 1 * 03: 03$ or 05:01 (Gonzalez-Galarza et al., 2018) which are not associated with PV. Similarly, alleles of group $D Q B 1 * 06$ occur in haplotypes bearing HLA-DRB1 alleles that belong to the $D R B 1 * 13$ and 15 groups. Moreover, structural differences between $D R B 1 * 03: 01$ and 07:01, and between the $D R B 1 * 13$ and 15 are great, resulting in distinct peptide-binding properties. For these reasons, $D Q B 1 * 02$ and $D Q B 1 * 06$ most likely are the protective alleles in the corresponding haplotypes. By contrast, allele $D Q B 1 * 03: 01$, also associated with low PV risk occurs in both protective $(D R B 1 * 11)$, and susceptibility haplotypes (DRB1*08:04) and cannot have a direct effect on PV.

As to pemphigus foliaceus, in the Brazilian population, increased susceptibility to FS is associated especially with alleles of the $H L A-D R B 1 * 01$ and $D R B 1 * 04$ groups (Petzl-Erler and Santamaria, 1989). The HLA-DRB1 alleles associated with highest risk are $D R B 1 * 01: 02$ and 04:04; additional significant associations occur with $D R B 1 * 01: 01$, 01:03, 04:06, 14:06, 16:01 (Moraes et al., 1997; Pavoni et al., 2003). Low risk alleles are $D R B 1 * 07: 01,03: 01,14: 02$, the allele group 08 (encompassing alleles 08:01, 08:02, 08:03, 08:04 and 08:07 in that population), group 11 (11:01, 11:02, 11:03, 11:04), and group 15 (alleles 15:01, 15:02, 15:03) (Table S2). It has been suggested that increased susceptibility could be associated with the motif LLEQRRAA of the amino acid residues 67-74 (Cerna et al., 1993; Moraes et al., 1997). However, a subsequent study concluded that HLA-DRB1 protein motifs do not add much to comprehension of the molecular basis of the HLA-DRB1 - FS associations (Pavoni et al., 2003).

When $H L A-D R B 1$ alleles were grouped in three categories, susceptibility (SU), protective (PR), and neutral (NE), an additive effect of SU was observed: the risk for SU/SU genotypes was about twice the risk for SU/NE geno- types; the PR/PR and PR/NE genotypes were equally highly protective; conversely, the PR/SU and NE/NE genotypes exhibited a neutral phenotype (Pavoni et al., 2003). A dominant effect of protective HLA alleles has been reported for other autoimmune diseases and may result from the action of autoantigen-specific regulatory $\mathrm{T}$ lymphocytes (Treg cells) (Ooi et al., 2017) (Figure 2)

As to $H L A D R B 1-D Q A 1-D Q B 1$ haplotypes, increased risk was observed for $D R B 1 * 01-D Q A 1 * 01: 01-D Q B 1 * 05: 01$. Decreased risk haplotypes were $D R B 1 * 07: 01-D Q A 1 * 02: 01$ $D Q B 1 * 02: 01, \quad D R B 1 * 03: 01-D Q A 1 * 05: 01-D Q B 1 * 02: 01$, and $D R B 1 * 11-D Q A 1 * 05: 01-D Q B 1 * 03: 01$ and $D R B 1 * 14: 02-D Q A 1 * 05: 01-D Q B 1 * 03: 01$ (Pavoni et al., 2003; Brochado et al., 2016) and $D R B 1 * 15-D Q B 1 * 06: 02$ (Moraes et al., 1991; Pavoni et al., 2003). It is difficult to identify the primary association or detect additive or epistatic gene-gene interactions because $H L A-D Q$ and $H L A-D R B 1$ alleles present high LD. However, the most constant markers of high risk are $D Q B 1 * 05$ and 03:02, while $D Q B 1 * 02,03: 01$ and 06 mark most low risk haplotypes (Table S2).

In Amerindian populations, a different picture emerges. In both the Xavante and the Terena populations, the FS susceptibility $H L A-D R B 1$ allele is 04:04, while $D R B 1 * 08: 02$ is associated with relative protection from the disease. An additional association with $D Q B 1 * 03: 02$ was seen in the Terena, which agrees with its high LD with DRB1*04:04 (Cerna et al., 1993; Moraes et al., 1997).

These results show that the most FS-HLA associations differ between Amerindians and the analyzed general Brazilian population (which is admixed but of predominantly European ancestry). The differences arise from the contrasting $H L A$ allele frequencies between these populations. South American Amerindians do not have alleles of groups $D R B 1 * 01, D R B 1 * 03, D R B 1 * 04: 06, D R B 1 * 07, D R B 1 * 11$, $D R B 1 * 15, D R B 1 * 16: 01, D Q A 1 * 01, D Q A 1 * 02, D Q B 1 * 02$, $D Q B 1 * 05, D Q B 1 * 06$, or present one or the other of these alleles at low frequency due to gene flow from non-Amerindians (Tsuneto et al., 2003, Gonzalez-Galarza et al., 2018).

In Tunisia, PF is endemic in the south and sporadic in the north. The analysis of $H L A-D R B 1$ and $D Q B 1$ revealed some differences between south and north Tunisia, and between PF in Brazil and in Tunisia. Increased susceptibility was associated with allele groups $D R B 1 * 03$ (south Tunisia) and 04 (in the whole sample), and haplotypes $D R B 1 * 04: 04$ $D Q B 1 * 03: 02$ (whole sample) and DRB1*04:02$D Q B 1 * 03: 02$ (north). Conversely, relative protection from $\mathrm{PF}$ was associated with the allele groups and haplotypes $D R B 1 * 11-D Q B 1 * 03: 01$ (south), $D R B 1 * 13-D Q B 1 * 06$ or 03 (whole sample), and $D R B 1 * 15-D Q B 1 * 06$ (south) and $D R B 1 * 04: 05-D Q B 1 * 03: 02$ (in north Tunisia) (Abida et al., 2009) (Table S2).

Most differences between Brazilians and Tunisians for PF-associated HLA class II alleles and haplotypes may be due to differing allele/haplotype frequencies, sample sizes, and statistical power. However, some may have a biological cause. The allele group $H L A-D R B 1^{*} 03$ is not associated with FS, for which the two $D R B 1^{*} 03$-bearing haplotypes 


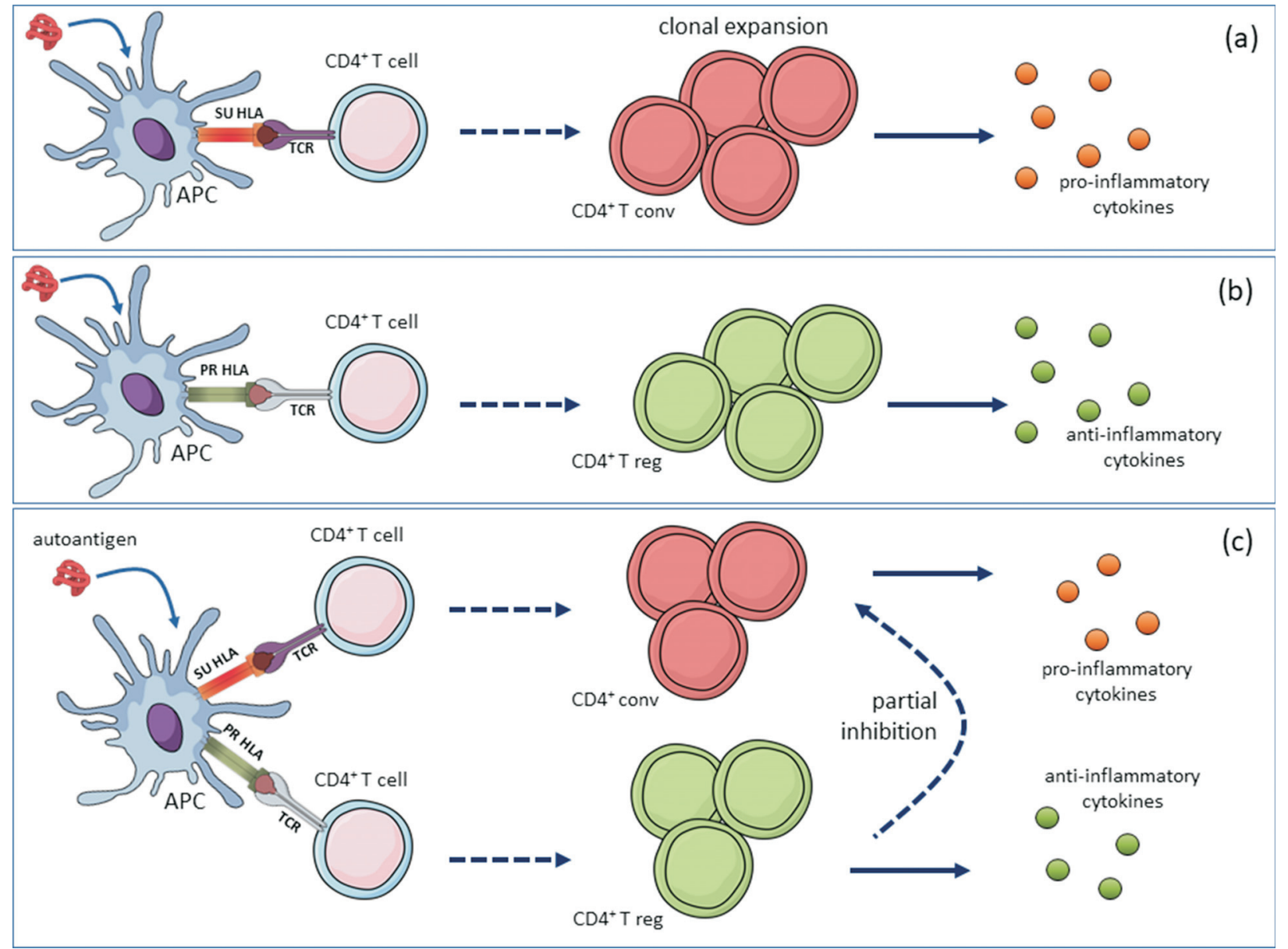

Figure 2 - Incompletely dominant effect of protective HLA alleles by antigen-specific regulatory T cells. When HLA class II alleles were grouped in three categories, susceptibility (SU), protective (PR), and neutral (NE), Pavoni et al. (2003) observed that SU/SU and SU/NE were susceptibility genotypes (a), while the PR/PR and PR/NE genotypes were highly protective (b); conversely, the PR/SU genotype resulted in a neutral phenotype, similar to that of NE/NE. According to the model shown, the partial inhibition of the autoagressive response by conventional effector T cell in individuals with a SU/PR genotype is provided by the anti-inflammatory response of regulatory T cells (model based on Ooi et al., 2017). APC: antigen-presenting cell, TCR: T cell receptor, $\mathrm{T}$ conv: conventional effector $\mathrm{T}$ cell, $\mathrm{T}$ reg: regulatory $\mathrm{T}$ cell.

have opposing effects on susceptibility (Table S2). So, allele $D R B 1 * 03: 01$, associated with lower FS risk in Brazil has been suggested to increase susceptibility to PF in Tunisia. The $D Q A 1-D Q B 1$ haplotypes associated with $D R B 1{ }^{*} 03$ alleles are the same in Brazil and Tunisia (Gonzalez-Galarza et al. 2018) and therefore cannot be the cause of the observed difference. Haplotypes that are common also in Tunisia but seemingly have no effect on PF susceptibility in that population are $D R B 1 * 07: 01-D Q A 1 * 02: 01-D Q B 1 * 02: 01$ or 03:01 and $D R B 1 * 01-D Q A 1 * 01: 01-D Q B 1 * 05: 01$, respectively associated with low and high risk of FS in Brazil. The discrepancy between the Tunisian and Brazilian populations may at least partially stem from different environmental triggering factors, or from differential LD with other not analyzed relevant MHC genes.

For sporadic PF in China (Sun et al., 2019; Zhang et al., 2019) the high risk markers were $D R B 1 * 04: 06,14: 05$ and $D Q B 1 * 03: 02,05: 03$. In a small sample of patients in France, $D R B 1 * 01: 02,04: 02,04: 06,14$ and $D Q B 1 * 03: 02$ are high risk markers; $D Q B 1 * 02$ is associated with de- creased risk (Martel et al., 2002) (Table S2). Most differences between sporadic PF on these populations and endemic PF in Brazil and Tunisia probably result from the distinct allele frequencies and statistical power.

\section{Other MHC genes}

The MHC is a region of about $4 \mathrm{Mb}$ at the cytogenetic location 6p21.33 that contains numerous genes distributed over three regions: class I, class III and class II. The MHC gene set includes classical and non-classical HLA class I and II genes and many additional genes whose products perform immune-related and unrelated functions.

- Non-classical HLA genes

Apart from HLA-A, B, C, DR, DQ, DP, all other HLA molecules are grouped as "non-classical". There are some noteworthy differences between the classical and non-classical HLA proteins and their genes, regarding functions, expression, and polymorphism (refer to O'Callaghan and Bell, 1998; Mellins and Stern, 2013). 
HLA-E is expressed on the surface of virtually every normal cell and plays a dual immunoregulatory role in innate and adaptive immune responses. It may present pathogenderived sequences, which elicit specific $\mathrm{T}$ lymphocyte responses, but the best-known function of HLA-E is the modulation of NK cell responses. HLA-E binds peptides derived from the signal sequence of HLA Ia molecules, mediating inhibitory signals via the CD94-NKG2A receptor, or activating signals via the NKG2C receptor when the HLA-G leader peptide is bound to HLA-E. So, it indirectly signals HLA class I expression, protecting healthy cells against lysis by NK cells, or allowing lysis of infected cells by NK cells when HLA Ia expression is abnormally low or absent, and HLA-G is upregulated (Lauterbach et al., 2015). Thus, HLA-E mediates self/non-self discrimination by NK cells, and this balance may be disturbed in pemphigus and other ADs.

In a case-control study of North American subjects, the frequency of homozygous HLA-E 01:03/01:03 individuals was significantly increased among PV patients. The data indicate that this association did not result from LD with PV-associated $H L A-D R B 1$ and $-D Q B 1$ alleles (Bhanusali et al., 2013). The $E^{*} 01: 03$ allele may increase susceptibility to other ADs as well. In a case-control study of rheumatoid arthritis (RA) in Poland, females (but not males) with the $E^{*}$ 01:03 allele were at higher risk, and 01:01/01:01 homozygotes were at lower disease risk. Also, patients bearing the 01:01/01:01 genotype achieved a significantly better outcome of anti-TNF treatment than patients with the $E^{*} 01: 03$ allele (Iwaszko et al., 2015).

The HLA-G molecule plays an immunoregulatory, tolerogenic role and interacts with several immune cells, through the CD8, LILRB1 and LILRB2, and KIR2DL4 receptors. HLA-G presents four membrane-bound and three soluble isoforms, restricted tissue expression, and limited nucleotide variability in the coding region, but high variability in the promoter and 3' UTR, which may influence HLAG levels (Donadi et al., 2011).

A significant increase of the HLA-G 14-bp deletion allele was observed in Jewish PV patients (Gazit et al., 2004). This indel polymorphism rs371194629 is in exon eight that specifies the 3' UTR region of the mRNA and has been implicated in posttranscriptional gene regulation and alternative splicing. In general, the 14-bp deletion allele has been associated with higher production of HLA-G, an effect that might be due to other polymorphisms in LD with rs371194629 (Donadi et al., 2011). The same and other HLA-G polymorphisms were associated with various diseases, including autoimmune disorders (Donadi et al., 2011).

Altered expression of HLA-G and imbalance of its isoforms was observed in epidermal cells of PV patients, suggestiong that HLA-G may act to diminish the deleterious effects of disease-promoting $\mathrm{T}$ lymphocytes or contribute to the homeostatic balance of the skin at the end of inflammation (Yari et al., 2008).

- Heat shock proteins of the HSP70 family

One of the first recognized functions of heat shock proteins (HSPs) is to chaperone other proteins, and most of them are upregulated during stressful conditions. Moreover, extracellular HSPs participate in the induction of cellular immune responses since they are involved in the antigen processing and presentation (de Jong et al., 2014). HSP70s are one of the most abundant sources of HLA class II ligands. Natural autoantibodies to HSP70s are common, and epitopes of HSP70s are recognized by Treg cells. However, exacerbated effector responses to HSP70s are associated with ADs. These findings demonstrate a complex relationship between autoimmunity and AD: natural autoimmunity to HSP70 is associated with health, whereas altered autoimmunity to HSP70 is related to disease. In this way, HSP70 could be essential autoantigens in balancing the healthy immune system (de Jong et al., 2014).

Three HSP70 family genes - HSPA1L, HSPA1A, and HSPA1B (often called HSP70-1, HSP70-2 and HSP70$H O M$, respectively) - are located in the MHC class III region. In a case-control and family study of PF in Tunisia with three tagging SNPs, increased frequencies of HSPA1L rs2227956 C>T (Thr493Met) allele $T$, HSPA1A rs 1043618 $G>C$ (a 5' UTR SNP) genotype $C / C$, and $H S P A 1 B$ $r s 1061581 G>A$ (a synonymous variant) genotype $G / G$ were observed among the patients in comparison to the control group. However, the significant LD between the HSP70 SNPs and the $H L A$ class II alleles, together with the results of the multivariate regression analysis could argue against a direct role of the $H S P 70$ polymorphism in susceptibility to $\mathrm{PF}$ (Toumi et al., 2015).

- Conflicting results for association between pemphigus and the transporter associated with antigen processing (TAP) genes.

TAP is a heterodimeric membrane molecule of the endoplasmic reticulum (ER) required for the transportation of peptides generated by the proteasome from the cytosol to the ER lumen, where they are loaded onto the HLA class I molecules. The TAP1 and TAP2 genes are located between the HLA-DQ and HLA-DP genes in the MHC. In a Japanese sample, the allele, haplotype and amino acid residue frequencies at each dimorphic site did not differ between PV and PF patients and controls, nor between patients grouped according to anti-DSG autoantibody profiles (Niizeki et al., 2004). However, in Israeli Jews, significant differences between PV patients and controls were detected in TAP2 polymorphic amino acid residue frequencies (Slomov et al., 2005).

\section{Variants of the MHC2TA (CIITA) gene indicate that the quantitative variation of MHC class II molecules also influences susceptibility}

The MHC2TA (also known as CIITA or C2TA) molecule is the master regulator of constitutive and IFN $\gamma$-induced expression of HLA class II genes in antigen-presenting cells. Mutations in the MHC2TA gene (cytogenetic location $16 \mathrm{p} 13.13)$ are responsible for the bare lymphocyte syndrome (BLS), type II, complementation group A (OMIM \#209920), a severe immunodeficiency in which patients fail to produce HLA class II molecules. Like several other immunodefi- 
ciencies, BLS also is often associated with autoimmune disorders. Patients have decreased numbers of Treg cells and fail to counterselect autoreactive mature naive B lymphocytes, suggesting that peripheral B cell tolerance also depends on HLA class II - T cell receptor (TCR) interactions (Hervé et al., 2007). Less detrimental variants of MHC2TA may have an impact in susceptibility to multifactorial diseases, notably HLA-associated diseases.

In a case-control study of FS, two SNPs were selected for association analysis. While the missense $r s 4774$ (Gly500Ala) SNP in the NACHT domain was not associated with FS, the $G$ allele of $r s 3087456$ in the promoter region was significantly associated with increased susceptibility in both the homozygous $G / G$ and the heterozygous $G / A$ states (Piovezan and Petzl-Erler, 2013). Additionally, a strong additive interaction between MHC2TA and HLA-DRB1 genotypes in FS disease susceptibility was observed: The odds ratio for individuals having two susceptibility $H L A-D R B 1$ alleles was 14.1 in the presence of the susceptibility $M H C 2 T A$ rs3087456 $G$ allele, but much lower (2.2) in the presence of the protective $M H C 2 T A A / A$ genotype. Based on these results, the hypothesis that genetically controlled levels of MHC2TA result in differential expression of the susceptibility and protective HLA class II molecules was raised. Thus, the quantitative variation of HLA molecules, in addition to their structural variation resulting from polymorphism of the coding regions, influences the risk of an individual developing pemphigus (Piovezan and Petzl-Erler, 2013). The same polymorphism also was associated with increased susceptibility to multiple sclerosis (MS), RA, and myocardial infarction (Swanberg et al., 2005).

MHC2TA has four promoters that control its expression in different cell types. The rs3087456 polymorphism can affect promoter III functionality that is responsible for the constitutive expression of MHC2TA in B lymphocytes, which are crucial for pemphigus autoimmunity. When leukocytes were stimulated ex vivo with IFN $\gamma$, lower expression of both the mRNA and the protein was seen for genotype $G / G$ in comparison to genotypes $A / A$ and $A / G$ (Swanberg et al., 2005).

Do polymorphisms of the desmoglein 1 and desmoglein 3 genes have an impact on pemphigus pathogenesis?

Four DSG genes are closely linked in chromosome 18, at the cytogenetic position $18 \mathrm{q} 12.1$. DSG 1 and DSG3 encode the major autoantigens in $\mathrm{PF}$ and $\mathrm{PV}$, respectively. Both genes are polymorphic. Several rare pathogenic variants of DSG1 result in autosomal dominant monogenic diseases palmoplantar keratoderma I (OMIM \#148700), and congenital erythroderma with palmoplantar keratoderma, hypotrichosis, and hyper-IgE (OMIM \#615508). Conversely, numerous benign SNPs that could play a role in susceptibility to polygenic disease occur in DSG1 and DSG3.

The question of whether genetic variants of DSG1 could play a role in PF was addressed in studies of French, Tunisian and Brazilian populations. Two polymorphic markers were analyzed. A haplotype comprising five missense variants in LD resulting from SNPs rs8091003, rs8091117, rs 16961689 , rs61730306, rs34302455 and corresponding to the extracellular domains EC4 and EC5 was not associated with PF, indicating that the structure of this portion of the molecule does not impact PF susceptibility (Martel et al., 2001). Though, allele $C$ of the synonymous rs 12967407 SNP at exon 7 $(809 \mathrm{~T}>\mathrm{C})$ was significantly more frequent in French and Tunisian PF patients than in the respective controls, especially in the homozygous $C / C$ state (Martel et al., 2001; Ayed et al., 2002). Additionally, interaction between DSG1 and HLA variants in PF susceptibility was observed by Martel et al. (2002). In FS the frequency of genotype $C / C$ also was increased in the patient sample, but the association was not significant ( $p=0.079$; Petzl-Erler and Malheiros, 2005). In that context, the unusually extended and strong LD between rs 12967407 and more than 100 polymorphisms, including SNPs in regulatory regions (Ensembl, Cunningham et al., 2019), is relevant and should be explored in future studies.

Significant associations between DSG3 variants and PV have been reported. Two related haplotypes were associated with PV in the British and Indian populations (Capon et al., 2006). In a follow-up study of the British sample, additional variants were examined, and the authors concluded that the association signal detected was due to other, regulatory rather than the previously examined coding SNPs $(\mathrm{Ca}-$ pon et al., 2009). So, as for DSG1 in PF, the question about the role of $D S G 3$ polymorphisms in PV pathogenesis is still open. Characterization of desmoglein regulatory elements and functional analysis are expected to identify sequence variants affecting gene expression and disease susceptibility.

\section{Genes in the leukocyte receptor complex (LRC): KIR, LAIR1, LAIR2}

The LRC on chromosome 19q13.42 comprises many genes for immunoglobulin-like cell surface receptors (Barrow and Trowsdale, 2008). It includes genes for the killer immunoglobulin-like (KIRs) receptors and the leukocyte Ig-like receptors (LILRs). The principal known ligands for both KIRs and LILRs are HLA class I molecules. Other Ig-family genes in the LRC are LAIRI and LAIR2 (leukocyte-associated Iglike receptors-1 and -2), natural cytotoxicity triggering receptor 1 (NCR1 also named NKp46 or LY94), receptor for Fc fragment of IgA (FCAR or CD89), and platelet glycoprotein VI (GPO), whose ligands are as diverse as immunoglobulins, viral hemagglutinins, and collagens. The LRC also contains NLR family members (NLRP or NALP, NLR family, pyrin domain-containing) that localize inside the cell and contribute for the activation of proinflammatory caspases via their participation in multiprotein complexes called inflammasomes. The impact of the LRC on complex disease susceptibility has been poorly explored, despite its evident importance in inflammation and immunity.

A genome-wide expression profiling with approximately 55,000 probes revealed that several genes in $19 q 13$ were differentially expressed in CD4+ lymphocytes when comparing FS patients and controls, as well as between dif- 
ferent FS clinical forms (Malheiros et al., 2014). Motivated by this result, recently the whole $1.5 \mathrm{Mb}$ LRC was screened in a case-control study using genotype data of 527 tag SNPs of which three were associated with differential susceptibility to FS (Farias et al., 2019). The intergenic SNP rs465169 is in a region that regulates several immune-related genes, including VSTM1, LAIR1, LILRA3-6, LILRB2, NLRP12, and $L E N G 8$. Increased risk was associated with its minor $A$ allele. The $L E N G 8$ rs35336528 and the FCAR rs 1865097 SNPs and four haplotypes with SNPs within the KIR3DL2/3, $L A I R 2$, and LILRBI were also associated with FS.

\section{The killer cell immunoglobulin-like receptor (KIR) and their HLA ligands modulate susceptibility to FS}

Natural killer (NK) cells belong to the family of innate lymphoid cells and are major players of innate immune responses, and also modulate adaptive immune responses. Various reports suggested a correlation of NK cell number and functional alterations with PV and other autoimmune conditions (Takahashi et al., 2007; Gianchecchi et al., 2018). NK cells express numerous receptors, including KIR that are also expressed in a subpopulation of cytolytic T lymphocytes.

There are inhibitory and activating KIR. The ligands for most activating KIR are unknown, but most inhibitory KIR bind HLA class I molecules. Cells with abnormally low classical HLA class I expression may escape recognition by cytotoxic CD8 T lymphocytes, but this renders these cells sensitive for NK-mediated killing. Hence, the cytotoxic response of NK cells occurs when activating signals predominate over inhibitory signals delivered by KIR-HLA (Kulkarni et al., 2008).

The genomic KIR region in the LCR is multigenic, but the number of KIR genes (gene content) varies widely, from 4 to 20 among KIR haplotypes. Each of these KIR genes presents multiple alleles. That normal variation does influence complex diseases and reproduction (Augusto and Petzl-Erler, 2015).

For FS, a protective association with activating KIR genes was observed in a study of KIR gene content polymorphism (Augusto et al., 2012). The presence of more than three activating genes apparently lowers the risk of FS significantly, and the strongest protective effect was found for higher activating/inhibitory KIR ratios. Furthermore, the presence of both the activating KIR3DS1 gene and its HLA-Bw4 ligand was protective. This contrasts with other ADs, where activating $K I R$ genes have been commonly reported to increase the risk. On the contrary, for infectious diseases reduced susceptibility is associated with activating KIR (Kulkarni et al., 2008). The authors hypothesized that this unusual association for a disease with autoimmune features might be related to the environmental trigger of FS. Possibly a viral or a salivary protein inoculated by a hematophagous insect initiates the pathogenic process. Thus, a more effective immune response against the initial triggering factor, with the participation of activating KIR, may prevent the early events that initiate the pathogenic process (Augusto et al., 2012).
In a subsequent investigation of KIR3DL2 alleles in FS, increased susceptibility was associated with allele $K I R 3 D L 2 * 001$ in an allele-dose and ligand-dependent manner: The risk was almost fourfold increased for KIR3DL 2*001/001 homozygotes, and for the presence of $K I R 3 D L 2 * 001$ together with at least one copy of the KIR3DL2 ligands HLA-A3 or HLA-A11. Moreover, a lower percentage of KIR3DL2-positive NK cells and lower expression of KIR $3 D L 2$ at the cell surface was seen for variant T (376Met) of SNP rs3745902 (1190C >T, Thr376Met). Amino acid 376 is in the cytoplasmic tail of the receptor and $376 \mathrm{Met}$ lowers the risk of FS. Because KIR3DL2 is an inhibitory receptor, lower susceptibility to FS may be due to decreased inhibitory signals within NK cells (Augusto et al., 2015). These results are in line with the gene content analysis commented above (Augusto et al., 2012).

\section{LAIR1 and LAIR2 gene variants are involved in gene expression and susceptibility to pemphigus foliaceus}

The leukocyte-associated immunoglobulin-like receptor 1 (LAIR-1, or CD305) is a collagen-binding inhibitory receptor necessary for the regulation of immune responses, expressed on most peripheral blood mononuclear cells (PBMC). The complement component $\mathrm{Clq}$ and collagen XVII are among the ligands of LAIR-1. LAIR-1 ligand engagement and crosslinking suppresses the function and/or differentiation of NK cells, T and B lymphocytes, dendritic cells and its precursors, and monocytes. The principal source of its secreted homolog LAIR-2 (or CD306) are T CD4+ lymphocytes. LAIR-2 functions as a natural competitor of LAIR-1 by binding the same ligands, thus restraining the inhibitory potential of LAIR-1 (Meyaard, 2008). Altered protein levels of LAIR-1 and LAIR-2 have been associated with autoimmune and inflammatory disorders, such as systemic lupus erythematosus (SLE), RA and autoimmune thyroid diseases (ATD) (see Camargo et al., 2016).

In a study of genome-wide mRNA levels in FS, both the LAIRI and the CIQA (that codes for the C1q ligand) mRNA levels were increased in CD4+ T lymphocytes of patients with disseminated (generalized) FS in comparison to unaffected controls (Malheiros et al., 2014).

Two of six analyzed LAIR1 tag SNPs (rs56802430 allele $G$ and $r s 11084332$ allele $C$ ) were respectively associated with increased and decreased susceptibility to FS, and one of eight LAIR2 tag SNPs (rs2287828 allele $T$ ) was associated with increased susceptibility in a case-control analysis for FS (Camargo et al., 2016). Furthermore, 4 to 5-fold increased susceptibility was seen for a haplotype of four LAIR2 SNPs that are not in LD with each other $\left(\mathrm{r}^{2} \leq 0.08\right.$; rs2042287, rs2287828, rs2277974, and rs 114834145; haplotype $G-T-C-A$ ). Alleles of four of the LAIR1 SNPs mark increased mRNA expression: $r s 3826753 G$, rs74463408 C, rs3745444 T, rs56802430 G; however, no link between LAIR1 expression and the disease was observed, leading to the conclusion that FS susceptibility by $L A I R 1$ polymorphisms is not a consequence of variable gene expression. Conversely, the same LAIR2 G-T-C-A haplotype is associated with both FS and 4.5-fold higher LAIR2 mRNA 
levels. The authors suggested that higher levels of the LAIR-2 protein are detrimental in FS by antagonizing LAIR-1 function and exacerbating immune responses (Camargo et al., 2016). Noteworthy, most LAIR1 and LAIR2 SNPs associated with FS or in high LD with them are in regions that present pre- or post-transcriptional regulatory features, such as chromatin modifications, regulatory RNA binding, or RNA splicing (Camargo et al., 2016).

\section{A regulatory 3' UTR polymorphism of KLRG1 influ- ences susceptibility to pemphigus foliaceus}

The killer cell lectin-like receptor subfamily G member 1 protein (KLRG1, alternatively MAFA, MAFAL or CLEC15A) is an inhibitory receptor expressed on the surface of mainly NK cells, and of CD4+ and CD8+ $\alpha \beta$ T lymphocytes with an effector or effector-memory phenotype. In addition to the inhibitory KIRs that regulate NK cell function via binding of HLA class I molecules on target cells (see above), NK cells also have inhibitory receptors specific for non-HLA ligands. KLRG1 monitors the expression of E-, Nand R-cadherins on target cells, mediating missing-self recognition by binding to a highly conserved site on these classical cadherins.

The KLRG1 gene is in the NK cell complex (NKC) in the chromosomal region $12 \mathrm{p} 13$. In an analysis of candidate SNPs chosen because of their putative ability to disrupt or create microRNA binding sites, increased FS susceptibility associated with the $A / G$ genotype of KLRG1 rs 1805672 compared with the $A / A$ genotype was seen. The KLRG1 $r s 1805672 \mathrm{G}$ allele disrupts a miR-584-5p binding site in the 3' UTR of $K L R G 1$; accordingly, KLRG1 mRNA levels were significantly higher in PBMC of $G$-positive individuals in comparison to individuals with genotype $A / A$. Functional analyses indicated that allele $G$ directly interferes with miR584-5p binding, allowing for KLRG1 mRNA (and possibly protein) accumulation, which in turn may contribute to the pathogenesis of FS (Cipolla et al., 2016). Interestingly, autoantibodies against the KLRG1 ligand E-cadherin (CDH1) were detected in sera of about half of PF patients and healthy subjects of an endemic area in Brazil, but not in healthy individuals from USA (Flores et al., 2012). It remains to be tested whether a relationship between increased KLRG1 levels, KLRG1-CDH1 binding, and anti-CDH1 autoantibodies exists in pemphigus.

\section{Genetic variants of some cytokines and cytokine re- ceptors have an impact on pemphigus susceptibility}

Cytokines are involved in immune responses and the regulation of numerous other biological processes. Many cytokine genes are polymorphic, and that diversity may have a functional impact, reflecting on susceptibility to complex diseases.

Interleukin 6 (IL-6) is an inducer of the acute phase response and acts on immune and non-immune cells. It is involved in monocyte and lymphocyte differentiation and is required for the generation of Th17 lymphocytes. Also, IL-6 plays an essential role in the terminal differentiation of B lymphocytes into immunoglobulin-secreting cells.

A significant association with the IL6 rs 1800795 $-174 \mathrm{G}>\mathrm{C}$ polymorphism was found for $\mathrm{FS}$, indicating that the $C / C$ genotype has a protective effect, while $G$ in the homozygous or heterozygous state is associated with increased susceptibility (Pereira et al., 2004). The rs 1800795 SNP is within the gene promoter. The $C$ allele is associated with lower plasma levels and lower in vitro expression in comparison to the $G$ allele (Fishman et al., 1998; Rivera-Chavez et al., 2003). Increased levels of IL-6 have been correlated with inflammatory and AD susceptibility, activity or more severe clinical symptoms (Mihara et al., 2012).

The rs2243250 SNP (also known as $-590 \mathrm{C}>\mathrm{T}$ or $-589 \mathrm{C}>\mathrm{T}$ ) in the promoter of the $I L 4$ gene was investigated for PF susceptibility in Brazil and Tunisia (Pereira et al., 2004; Toumi et al., 2013). In both studies, the $T / T$ genotype was increased in the patient samples in comparison to the control samples. Interestingly, the $T / T$ genotype expresses higher mean serum levels of IL-4 compared to the $C / T$ and $C / C$ genotypes (Toumi et al., 2013). Higher IL-4 levels might be contributing to the polarization of autoreactive Th lymphocytes towards the Th2 pathway, inducing proliferation of autoreactive B lymphocytes and facilitating immunoglobulin class switching to IgG4 that is pathogenic in pemphigus. The $I L 4 R$ gene (also known as $I L 4 R A$, in $16 \mathrm{p} 12.1$ ) encodes the IL-4R $\alpha$ chain of the heterodimeric receptors for IL-4 and IL-13. Toumi et al. (2013) observed a positive association of $\mathrm{PF}$ in Tunisia with the $T ; A-C-A$ combination for rs2243250 (of IL4), and rs4787948-rs3024622-rs3024530 (of $I L 4 R$ ), raising the hypothesis that genetic variation of IL-4 and IL-4R $\alpha$ interact and play a central role in the regulation of pathogenic IgG4 antibody production or the clinical course of the disease. In contrast, polymorphisms of the IL13 gene and IL13RA2 (that encodes one IL-13 receptor chain; located in Xq24) were not associated with the disease (Toumi et al., 2013).

Pemphigus has been considered a Th2 disease. However, support for the involvement of the IL23/Th17 pathway in the pathogenesis of pemphigus was found. In Tunisian PF, a higher frequency of circulating Th17 cells was observed in patients' blood compared to controls. Eleven tag SNPs in the IL23/Th17 axis genes IL23R (interleukin 23 receptor), IL17A (interleukin 17A), ILI7F (interleukin 17F), IL17RA (interleukin 17 receptor A), RORC (ROR $\gamma \mathrm{t}$ ), TNF (tumor necrosis factor) and STAT3 (signal transducer and activator of transcription 3) genes were selected. The IL23R rs 11209026 $G / G$ genotype, the $I L 17 A$ rs3748067 C/C genotype, the IL $17 F$ rs $763780 C$ allele, and the $T N F-308 G>A$ rs 1800629 $A$ allele (in both the $A / A$ and $A / G$ genotypes) were associated with increased susceptibility (Ben Jmaa et al., 2018).

The favored hypothesis about mechanisms underlying the associations of pemphigus with cytokine polymorphisms is that individuals with different genotypes for regulatory polymorphisms express different cytokine levels that may impact pathogenesis. The disease-associated IL6,IL4, IL4R and TNF SNPs cited above are eQTL (expression quantita- 
tive trait loci, which influence the transcription level of one or more genes) according to the GTEx Portal (Carithers et al., 2015). Altered levels of cytokines were observed in the sera and lesional skin of pemphigus patients and possibly play a role in pathogenesis and disease severity (Ameglio et al., 1999; Zeoti et al., 2000; Timóteo et al., 2017a,b; Ben Jmaa et al., 2018). Moreover, the altered cytokine levels that occur in ADs are among the causes of the wide variation in responsiveness to glucocorticoid therapy. Augmented production of inflammatory cytokines may downregulate glucocorticoid receptor expression, resulting in diminished or lacking response to treatment (Yang et al., 2012). Decreased glucocorticoid sensitivity associated with higher levels of IL-6 and TNF $\alpha$ was seen in vitro for PBMC from pemphigus patients (Chriguer et al., 2012).

Genetic variants and the expression level of the BAFF cytokine has also been investigated in pemphigus and will be discussed in the following topic.

\section{The B lymphocyte co-stimulators CD40, CD40LG,} BAFF, and CD19

A role for $C D 40, C D 40 L G$ and $B A F F$ polymorphisms in pemphigus finds support in studies of protein or mRNA levels in PF and PV, and in the effects of these molecules and their genetic variants in homeostasis, in inflammation, and ADs.

CD40 (TNFRSF5) is a co-stimulatory molecule at the surface of a variety of cells like B lymphocytes, macrophages, and dendritic cells. In the skin, Langerhans cells and keratinocytes constitutively express CD40. Its ligand CD40LG (also known as CD40L TNFSF5, CD154, TRAP) is expressed at the surface of activated but not resting CD4+ $\mathrm{T}$ lymphocytes, and other hematopoietic and nonhematopoietic cells.

CD40/CD40LG interaction induces intracellular signals and expression of surface and secreted molecules required for antibody- and cell-mediated adaptive immune responses The CD40/CD40LG interactions also are essential for peripheral B lymphocyte tolerance. Lack of functional CD40LG or CD40 results in the monogenic immunodeficiency syndromes called hyper IgM syndrome type 1 (Xlinked, OMIM \#308230) and type 3 (autosomal recessive, OMIM \#606843), respectively. Patients present normal or elevated serum IgM levels associated with markedly decreased $\operatorname{IgG}, \operatorname{Ig} \mathrm{A}$, and $\mathrm{IgE}$, and reduced Treg frequency, as well as impaired immunoglobulin somatic hypermutation, class switch recombination, and repertoire selection. The patients are susceptible to recurrent or opportunistic infections and autoimmune manifestations.

The CD40LG gene is located at Xq26.3. The risk of FS is increased by homozygosity (in women) or hemizygosity (in men) for the major $T$ allele of SNP rs3092945 $(-726 \mathrm{~T}>\mathrm{C})$. No association was seen for $r s 56074249$ a 3 ' UTR(CA) short tandem repeat (STR, or microsatellite) (Malheiros and Petzl-Erler, 2009).

The CD40LG rs3092945 SNP has not been considered as a marker in other studies of ADs, because it is absent or very rare all over the world, except for sub-Saharan African and some admixed populations of South and North America. However, associations with other polymorphisms of the CD4OLG gene or close to it the were seen for ADs such as celiac disease, ulcerative colitis, and Crohn's disease (Li et al., 2015).

The CD40 gene is at the cytogenetic location 20q13.12. The 5' UTR polymorphism -1C $>$ T ( rs 1883832) was analyzed in FS. This SNP resides in the Kozak sequence that includes the translation initiation codon (AUG) and the surrounding nucleotides and is important for ribosome binding to the mRNA. The $r s 1883832 T$ allele was significantly associated with decreased susceptibility to FS, consistent with a dominant or additive protective effect. Accordingly, the $C / C$ genotype was associated with increased susceptibility to FS (Malheiros and Petzl-Erler, 2009).

Involvement of CD40/CD40LG levels was observed in the pathogenesis of pemphigus. Upregulation of both the receptor and the ligand has been reported in lesional skin and the serum of patients with active PV and PF. Numerous CD40LG + cells and CD40LG mRNA copies were seen in lesional specimens compared to controls, and immunostaining for CD40 was intense both in the dermis and in keratinocytes. Additionally, patients' sera contained high levels of sCD40LG that is mainly secreted by activated $\mathrm{T}$ lymphocytes (Caproni et al., 2007).

In FS patients, there is an increased number of dendritic cells in lesional skin, and this correlates with serum autoantibody titers (Chiossi et al., 2004). It has been shown that the CD40 rs $1883832 \mathrm{C}$ allele increases the translational efficiency of nascent mRNA, resulting in $15 \%$ to $32 \%$ more CD40 protein than that seen for the $T$ allele (Jacobson et al., 2005). Altogether, these findings support the hypothesis that higher levels of CD40 in individuals with the rs1883832 C allele may contribute to the pathogenesis of FS.

Variable susceptibility to ATD, SLE and RA also is associated with $C D 40$ polymorphisms, especially in Europeans and specifically with the intron SNP rs 4810485 that is a proxy for $r s 1883832\left(\mathrm{r}^{2} 1 \mathrm{in}\right.$ all analyzed non-African populations; 1000 genomes via LDlink) (Lee et al., 2015a,b).

The $B A F F$ (TNFSF13B) gene maps to $17 \mathrm{p} 13.1$. The B cell activating factor (BAFF, also known as BLYS, TNFSF13B, TALL1, THANK) is predominantly produced by myeloid cells, but regulated expression by many different hematopoietic and non-hematopoietic cell types has been described (Vincent et al., 2013). BAFF is initially expressed as a membrane-bound trimer, which is proteolytically cleaved and released in a soluble form. Among its multiple effects, BAFF is a critical regulator of B lymphocyte differentiation, maturation, and survival. It is also involved in the immunoglobulin switch from $\operatorname{IgM}$ to $\operatorname{IgG}$, IgE, and $\operatorname{IgA}$. The homologous proliferation-inducing ligand (APRIL, TNFSF13A or TALL2) also has multiple effects in B lymphocyte biology; however, a possible impact of its genetic variants in pemphigus has not yet been published.

For FS, a weak protective association was found with the $T$ allele of the $r s 9514828 \mathrm{SNP}(-871 \mathrm{C}>\mathrm{T}$, upstream of the $B A F F$ gene transcription initiation site) (Malheiros and 
Petzl-Erler, 2009). This SNP is in the binding site of transcription factor MZF1 and may change its binding affinity, resulting in altered levels of BAFF (Kawasaki et al., 2002). MZF1 was reported to be preferentially expressed in differentiating myeloid cells (Hromas et al., 1991). In a genomewide mRNA expression profile in FS, BAFF expression was significantly increased in CD4+ T lymphocytes of patients with active disease and decreased in patients under immunosuppressive treatment, both compared to healthy individuals, and also overexpressed in lesional skin compared to non-lesional skin of the same patients (Malheiros et al., 2014). However, the 3' UTR SNPs rs4145212, rs116898958, and rs 185198828 that may alter the binding sites of microRNAs were not associated with FS (Cipolla et al., 2016).

Remarkably, regarding susceptibility to FS, gene-gene interactions may occur between $B A F F$ and both $C D 40$ and $C D 40 L G$. So, the protective effects of CD40LG rs3092945 C and $C D 40$ rs $1883832 T$ alleles only manifest in $B A F F$ rs9514828 T-positive individuals, and vice versa (Malheiros and Petzl-Erler, 2009). This is not unexpected given the functional interactions between CD40, CD40LG, and BAFF in health and disease, and the effect of the genetic variants on protein levels. Notwithstanding, additional studies are needed to validate the associations and to understand their causes.

Functional effects of BAFF genetic variation have also been reported for SLE and MS in Sardinia (Steri et al., 2017). Circulating BAFF levels are often elevated in patients with SLE and correlate with clinical disease activity. Elevated levels of BAFF were reported in the serum of RA and Sjögren's syndrome as well, but not PV (Asashima et al., 2006).

The B lymphocyte antigen CD19 is expressed by early pre-B cells from the time of heavy chain rearrangement until plasma cell differentiation, and by follicular dendritic cells. Antigen-induced B cell receptor signaling is modulated by a multimolecular complex on the membrane of B lymphocytes of which CD19 functions as the principal component. CD19 is required for optimal antibody responses and selection against inherent autoreactivity. The autosomal recessive common variable immunodeficiency 3 (CVID3, OMIM \#613493) is caused by lack of functional CD19. Among other alterations of B lymphocyte immunity, selection against the autoreactive properties of immunoglobulins is defective in patients (van Zelm et al., 2014).

Recently, a unique CD19 ${ }^{\text {hi }}$ B lymphocyte population exhibiting activation and memory-like properties was detected in the periphery of pemphigus patients. Genes involved in B lymphocyte activation and differentiation were up-regulated in these B cells. A tight correlation between peripheral CD19 ${ }^{\text {hi }} \mathrm{B}$ cells and total $\mathrm{IgG} / \mathrm{IgM}$ levels was seen. These cells might contain B lymphocyte precursors for terminal differentiation and contribute to $\mathrm{IgG} / \mathrm{IgM}$ production in ADs (Liu et al., 2017).

These observations motivated the search for a possible association of FS with $C D 19$ variants. Two polymorphisms of the CD19 gene (mapped to 16p11.2), intron SNP IVS14 $-30 \mathrm{C}>\mathrm{T}$ and an STR at the 3' UTR were used as markers.
They had been previously associated with susceptibility to SLE in the Japanese population (Kuroki et al., 2002). For pemphigus, no significant differences between the patient and control samples were seen such that these polymorphisms do not play any crucial role in the inter-individual variation of susceptibility (Malheiros and Petzl-Erler, 2009). Given these observations and the scarcity of studies, it would be premature to conclude that genetic variation of CD19 is irrelevant for pemphigus.

\section{Common genetic variants of the molecules involved in $\mathrm{T}$ lymphocyte activation and tolerance may influ- ence susceptibility to pemphigus.}

Adequate $\mathrm{T}$ lymphocyte response to antigen requires specific interaction of the peptide-HLA complex with the $T$ cell receptor, as well as co-stimulatory and co-inhibitory signals that regulate activation, proliferation, and termination of the $\mathrm{T}$ cell response. The balance between positive and negative signals determines the outcome; hence, disruption of that balance may result in disease. These co-regulatory signals are provided by membrane-bound receptor-ligand pairs of which the most prominent are CD28/CTLA4:CD80/CD86, ICOS:ICOSL, and PD-1 (or PDCD1):PD-L1(CD274)/PD-L2, which are members of the immunoglobulin superfamily.

CD28-CD80/CD86 is the classical T lymphocytes costimulatory pathway. CTLA4 (or CD152) is an inhibitory receptor that can outcompete CD28, binding to CD80 and CD86 with higher affinity than CD28 and limiting T cell responses (Goronzy and Weyand, 2008). ICOS is an important co-stimulatory receptor, especially for Th2 effector cells. While CD28:CD80/CD86 interactions are critical for the initiation of an effective immune response, ICOS:ICOSL is required at later stages and predominates over CD28 for secondary immune responses (Coyle et al., 2000). ICOS is critical for humoral immune responses. The co-inhibitory molecules PD-L1 and PD-L2 interact with the PD-1 receptor to suppress responses by T lymphocytes (Keir et al., 2007).

Haploinsufficiency of, or impaired ligand binding to, CTLA4 result in a rare autosomal dominant immune dysregulation syndrome with incomplete penetrance named autoimmune lymphoproliferative syndrome type V (ALPS5 or CHAI; OMIM \#616100). Common variable immunodeficiency 1 (CVID1; OMIM \#607594) is an autosomal recessive disease due to mutations in ICOS.

For FS in Brazil, nineteen polymorphic markers were analyzed. For region 2q33.2, seven SNPs and three STR were selected, ranging from the promoter region of the CD28 gene to the intergenic region between CTLA4 and ICOS. A protective effect of allele T of CTLA4 rs5742909 $(-318 \mathrm{C}>\mathrm{T})$ was detected, while for CTLA4 rs733618 ( $-1722 \mathrm{~T}>\mathrm{C}$ ) the $C$ allele was associated with increased susceptibility. Another CTLA4 SNP rs 139105990 in a putative microRNA binding site is not associated with FS (Cipolla et al., 2016). For region 3q13.33, seven polymorphisms in the CD80 promoter and one missense SNP of the CD86 gene 
were analyzed. Significant associations occurred for CTLA4 and CD86 SNPs, and the STR (Dalla-Costa et al., 2010).

The rs5742909 $T$ allele marks higher promoter activity (Wang et al., 2002) and increased expression of CTLA4 (Ligers et al., 2001), which could lower the risk of ADs.

The $r s 733618$ risk allele $C$ might lead to altered alternative splicing and decreased expression and function of membrane-bound CTLA4, resulting in impaired inhibition of T lymphocyte activation, which might contribute to the development of $\mathrm{AD}$, as suggested for myastenia gravis (MG) (Wang et al., 2008).

In the sample of predominantely African ancestry, lower risk of the disease was associated with allele $A$ of the CD86 rs 1129055 (1057G >A, Ala304Thr) SNP, particularly when in homozygosis. This allele may alter the intracellular signal transduction pathways controlled by the CD86 molecule on antigen presenting cells; however, the lack of association in the Euro-Brazilian sample argues against a direct effect of the $r s 1129055$ polymorphism in susceptibility.

Three PDCD1 polymorphisms were analyzed in FS: rs11568821 (PD1.3, in intron 4), rs2227981 (PD1.5, a synonymous SNP), rs 10204525 (PD1.6, a 3' UTR SNP). The rs 10204525 may influence binding of microRNA and transcription factors, altering the expression of PD-1. Its major allele $A$ was over-represented among the patients of predominantly European ancestry, but not in the Afro-Brazilian sample (Braun-Prado and Petzl-Erler, 2007).

Analysis of a small sample of Polish PV $(n=40)$ and PF $(n=14)$ patients showed no statistically significant differences between the patients and the controls for the CTLA4 missense polymorphism rs231775 (+49A $>$ G; Thr17Ala). For ICOS, carriers of the allele $C$ of $r s 10932029$ $($ IVS1+173T $>$ C) were more frequent between each of both patient samples in comparison with the control sample (Narbutt et al., 2010).

\section{Genetics sheds light on the controversial relevance of the complement system in pemphigus}

A primary message given by associations between complex diseases and (inherited) genetic polymorphisms is that the (mostly still unknown) mechanisms linking the genotype to disease susceptibility are causal in (rather than a consequence of) the pathogenic process.

The complement system (CS) consists of a large number of soluble and membrane-bound proteins and represents one of the major effector mechanisms of innate immunity against pathogens, and for removal of cellular debris and immune complexes. The role of complement in pemphigus has been a controversial issue, mainly because pathogenic antidesmoglein autoantibodies mostly belong to the IgG4 subclass that does not initiate the classical complement pathway, and because acantholysis in pemphigus does not require complement in vitro. However, the alternative and the lectin complement pathways are not initiated by antigen/antibody complexes. Moreover, the CS is emerging as a global regulator of immune responses and tissue homeostasis, beyond its well-known role in innate immunity
(Hajishengallis et al., 2017, and others). Please refer to the recent article by Bumiller-Bini et al. (2018) for an appraisal of the debate about the role of complement in pemphigus.

Motivated by prior observations of altered expression of CD59 - the most essential MAC inhibitor - in several ADs, the hypothesis that SNPs in noncoding regions may regulate CD59 expression levels and participate in autoimmune pathogenic processes was tested in a recently published work (Salviano-Silva et al., 2017). Six intronic and 3' UTR polymorphisms that might affect alternative splicing of the primary RNA transcript or regulation of mRNA stability in the cytoplasm were analyzed in a case-control FS association study, and for a possible effect on transcript levels. Specific alleles and haplotypes influenced disease susceptibility as well as mRNA expression levels, especially in women. The risk haplotype $G-G-C-C-A-A$ also marked higher mRNA expression. The authors concluded that higher $C D 59$ transcriptional levels might increase susceptibility to FS (especially in women), possibly due to the role of CD59 in T lymphocyte signal transduction (Salviano-Silva et al., 2017). Association with rs 1047581 was replicated in a subsequent study (Bumiller-Bini et al., 2018, see below).

The complement receptor 1 (CR1, or CD35) plays a major role in inhibiting the complement system, removing immune complexes, and activating B cells. The gene contains several functional polymorphisms that have been associated with different multifactorial diseases (please refer to Oliveira et al., 2019). In a study of FS, 11 CR1 SNPs were analysed. Among these were the SNPs that define the Knops blood group system (York and McCoy antigens on erithrocytes). The haplotypes $C R I * 3 B 2 B$ (York) and $C R I * 3 A 2 A$ (with p.1208Arg) were associated with protection, and the $C R 1 * 1$ haplotype (McCoy) with increased susceptibility. Furthermore, heterozygote $r s 12034383 \mathrm{~A} / G$ individuals presented higher CR1 mRNA levels than $G / G$ homozygotes. The lowest soluble CR1 (sCR1) levels occurred in patients with active, more severe (generalized) disease, but treatment and remission resulted in the increase of median sCR1 levels. So, genetic variants of CR1 seem to modulate susceptibility to the disease and higher sCR1 levels may have an anti-inflammatory effect in patients with FS (Oliveira et al., 2019).

A region in chromosome 9q33.2 that includes the complement component $C 5$ gene and the TNF receptor-associated factor 1 gene (TRAF1) had been identified as a susceptibility and severity factor for diverse diseases, such as RA and SLE (Kurreeman et al., 2010). The SNP rs 10818488 is an eQTL for different genes and could have a functional impact on C5 synthesis. Even so, this regulatory intergenic SNP was not associated with PF and PV in the Tunisian population (Mejri et al., 2009). In line with this result, C5 polymorphisms were also not associated with FS (BumillerBini et al., 2018).

In a recent comprehensive study, 992 SNPs distributed within $44 \mathrm{CS}$ genes were analyzed in a case-control study of FS (Bumiller-Bini et al., 2018). Evidence for association was seen with variants of 10 genes that encode most of the complement proteins previously detected in the skin or pre- 
senting altered serum levels in patients (Table 1): C3 (complement component 3), C5AR1 (complement component 5a receptor 1 , the primary receptor for $\mathrm{C} 5 \mathrm{a}$ anaphylatoxin), C8A (complement component 8 , alpha subunit, a component of the membrane attack complex MAC), C9 (complement component 9 of the MAC), CD59 (MAC inhibitor), $C F H$ (complement factor $\mathrm{H}$, the major regulator of the alternative pathway), CR2 (complement receptor 2), ITGAM (integrin alpha-M or $\mathrm{CR} 3$, the alpha chain of a receptor for the $\mathrm{iC} 3 \mathrm{~b}$ fragment of C3), ITGAX (integrin alpha-X, or CR4, the alpha chain of a receptor for the $\mathrm{iC} 3 \mathrm{~b}$ fragment of the $\mathrm{C} 3$ ), and MASP1 (mannan-binding lectin serine protease 1, an essential protein in the lectin pathway of complement) (BumillerBini et al., 2018).

\section{Epigenetic alterations of DNA and histones}

In recent years, the involvement of epigenetic alterations in inflammatory and autoimmune diseases has been recognized and attracted much interest (Nielsen and Tost, 2013; Picascia et al., 2015; Zhang and Lu, 2018). However, the molecular mechanisms underpinning these epigenetic changes in diseases are still poorly understood. Most studies on the effect of epigenetic mechanisms on complex diseases have been restricted to evaluation of the DNA methylation pattern.

For autoimmune skin diseases, it was observed that deregulation of DNA and histone methylation contributes to PV (Zhao et al., 2012), psoriasis (Chandra et al., 2015; O'Rielly et al., 2015), systemic lupus erythematosus (SLE) (Hung et al., 2018) among other. In PBMCs of patients with PV, genomic DNA methylation was increased relative to controls. DNA methyltransferase 1 (DNMT1) expression levels were significantly higher and methyl-CpG binding domain protein 3 (MBD3) levels were downregulated in patients compared with healthy controls. Global histone $\mathrm{H} 3 / \mathrm{H} 4$ acetylation and H3K4/H3K27 methylation levels were significantly decreased in patient compared with healthy controls. These changes were accompanied by increased histone deacetylase 1 and 2 (HDAC1, HDAC2) and suppressor of variegation 3-9 homolog 2 (SUV39H2), and decreased SUV39H1 and enhancer of zeste 2 polycomb repressive complex 2 subunit (EZH2) in PV PBMCs (Zhao et al., 2012).

For pemphigus, there are no published studies of variants in genes that act on epigenetic mechanisms, except for a recent study of FS (Spadoni et al., 2020). A total of 566 polymorphisms in 63 genes that code for lysine methyltransferases (KMT), demethylases (KDM), DNA methyltransferases (DNMT) and ten-eleven translocation demethylases (TET) were considered in a case-control association study. Eleven SNPs in four genes were associated with FS: In the histone lysine demethylase $4 \mathrm{C}$ gene $K D M 4 C$ (3 SNPs) and in the histone lysine methyltransferases genes SETD7/KMT7 (1 SNP), MECOM/KMT8E (5 SNPs), and PRDM16/KMT8F (2 SNPs). The results of the study indicate that dysregulated histone (de)methylation plays a major role in pemphigus pathogenesis.
Associations with variants of genes involved in regulated cell death pathways yield insight into the poorly understood cell death mechanism in pemphigus

Twelve regulated cell death (RCD) routes have been recognized: intrinsic apoptosis, extrinsic apoptosis, mitochondrial permeability transition (MPT)-driven necrosis, necroptosis, ferroptosis, pyroptosis, parthanatos, entotic, NETotic, lysosome-dependent, autophagy-dependent and immunogenic pathways (Galluzzi et al., 2018). To date, only apoptosis has been considered in pemphigus, with controversial results about its role in the loss of cell adhesion and cell death. Some authors stated that cell death occurs by apoptosis (Gniadecki et al., 1998; Rodrigues et al., 2009), while others argued that there is no clear evidence of the occurrence of such an event in pemphigus (Lee et al., 2009; Schmidt et al., 2009; Janse et al., 2014; Sokol et al., 2015).

Frequencies of 1,167 SNPs from genes encoding products of all the 12 well-established cell death cascades were compared between FS patients and healthy control individuals (Bumiller-Bini et al., 2019). Ten gene variants belonging to six cell death pathways differed significantly between these two population samples: necroptosis (TNF and $T R A F 2$ ), apoptosis (TNF, CD36 and PAK2), pyroptosis $(P R K N)$, immunogenic cell death (CD47, SIRPA and $E I F 2 A K 3)$, parthanatos (HK1) and necrosis (RAPGEF3). The genetic association profile with $T N F, T R A F 2, C D 36$ and $P A K 2$ variants marks decreased susceptibility to FS and higher TNF and TRAF2 levels and lover CD36 levels. This profile may favor cell survival and inflammation instead of apoptosis/necroptosis. Conversely, higher susceptibility is marked by variants of $C D 47$ and SIRPA of the immunogenic cell death pathway, proposed to lead to increased internalization of cell debris and antigen presentation, which may increment autoantibody production in FS.

\section{Receptors for the Fc portion of immunoglobulin $G$}

Low-affinity Fcy receptors bind the Fc portion of polymeric IgG in antigen-antibody immune complexes. They are cell-surface receptors expressed by different immune cells and mediate inflammatory responses. IgG binding can either activate or inhibit downstream cellular responses depending on the presence of ITAM or ITIM in the intracellular portion of the engaged Fc $\gamma$ receptor. Dysregulation of Fc $\gamma$ receptors is critical in diverse inflammatory and ADs (see Recke et al., 2015).

Five closely linked paralogous genes at the cytogenetic location 1q23.3, FCGR2A, FCGR2B, FCGR2C, $F C G R 3 A$, and $F C G R 3 B$, encode the low-affinity receptors Fc $\gamma$ RIIa, Fc $\gamma$ RIIb, Fc $\gamma$ RIIc, Fc $\gamma$ RIIIa, and Fc $\gamma$ RIIIb, respectively. Copy number variation occurs by deletion or duplication of $F C G R 3 A$ and $F C G R 2 C$ together, or FCGR3B and FCGR2C together, but not FCGR2A or FCGR2B. Common single-nucleotide variation within and between the paralogs adds another layer of complexity to the FCGR region.

Recke et al. (2015) estimated the effect of the patient FCGR genotype on the risk to develop PV/PF or BP (bullous pemphigoid) in a case-control study. The risk of PV/PF was decreased in the presence of allele $\mathrm{C}$ of the promoter polymor- 
phism $r s 3219018(-386 \mathrm{G}>\mathrm{C})$ that affects the binding of transcription factors and expression levels of Fc $\gamma \mathrm{RIIb}(F C G R 2 B)$ and increased in the presence of an FCGR2C rs 183547105 $O R F$ allele. Because the inhibitory Fc $\gamma$ RIIb is involved in peripheral tolerance of B lymphocytes, which may be counterbalanced by functional Fc $\gamma$ RIIc expression, the authors proposed that these polymorphisms alter the risk of PV/PF due to a shift of the threshold for activation and proliferation of autoreactive B lymphocytes (Recke et al., 2015).

\section{Does the variation of the forkhead box P3 gene FOXP3 have any impact on pemphigus foliaceus?}

The FOXP3 gene is located at Xp11.23 and mutations in its coding region cause IPEX, the monogenic X-linked immune dysregulation, polyendocrinopathy, and enteropathy (OMIM \#304790). Susceptibility to some multifactorial ADs has been associated with $F O X P 3$ polymorphisms (Oda et al., 2013). FOXP3 is a candidate for diseases with an immune background because it codes for a transcription factor of prime importance for the regulation of immune responses by $\mathrm{T}$ lymphocytes and in development of CD4+ CD25(IL2RA)+ Treg cells, which are critical for suppression of autoimmune or otherwise inappropriate immune responses. DSG3-induced Treg cells that inhibited autoreactive Th clones were preferentially isolated from the peripheral blood of healthy individuals who carried the PVassociated HLA class II alleles, HLA DRB1*04:02 and $D Q B 1 * 05: 03$, and only from a minority of patients with PV. These results strongly suggest that these Treg cells may be involved in the maintenance of self tolerance against DSG3 (Veldman et al., 2004).

Thus far, only in Tunisia PF has been analyzed in search of a possible influence of $F O X P 3$ variants in susceptibility. In a sample of women, the intronic SNPs rs3761547 allele $G$, rs3761548 A, rs3761549 C, and $r s 2294021 C$ were associated with increased susceptibility to endemic PF. For sporadic PF, a weak association was seen only with $r s 3761549 C$ in the individual analysis, but higher susceptibility to both endemic and sporadic PF was associated with haplotype $G-A-15-C-C$ where 15 stands for the allele of a $(\mathrm{GT})_{\mathrm{n}}$ STR in the promoter region (Ben Jmaa et al., 2017). The genomic region of chromosome $\mathrm{X}$ that includes the FOXP3 gene bears many protein-coding and noncoding RNA genes whose SNPs present very high LD $\left(\mathrm{r}^{2} \geq 0.8\right)$ (1000 genomes via LDlink). The four SNPs analyzed in that study mark three different LD blocks. It would be relevant to verify if the association can be validated in other populations and for the various forms of pemphigus.

\section{The ST18 gene}

ST18 encodes a transcription factor (zinc finger protein 387; ZNF387) and regulates apoptosis and inflammation, two processes relevant to pemphigus pathogenesis. ST18 expression was upregulated in the skin of PV patients. The secretion of TNF $\alpha$, IL-1 $\alpha$, and IL-6 that were reported to be increased in the lesioned skin of PV patients. In functional assays, these same cytokines were increased by $S T 18$ overexpression in the presence of PV serum or PV IgG. A1lele A of the $S T 18$ polymorphisms rs 2304365 was associated with PV in Jews and Egyptians, but not in Germans (Sarig et al., 2012). Subsequently, high LD between SNPs rs 2304365 and rs 17315309 was detected in Jews, and the authors concluded that the functional SNP rs 17315309 allele G, which drives ST18 upregulation possibly is the causal polymorphism (Vodo et al., 2016). The risk allele $r s 2304365 \mathrm{~A}$ was associated with severe pemphigus and a higher age of disease onset in the Iranian population (Etesami et al., 2018). In the Chinese population, no association with rs2304365 was seen for PV and PF (Yue et al., 2014). The apparently conflicting results between the association studies in the Jewish and Chinese populations can be explained by the absence of the risk allele $r s 17315309 G$ in Eastern Asian populations (Ensembl, Cunningham et al., 2019). However, the rs $17315309 \mathrm{G}$ allele is common, and LD with $r s 2304365$ is high in Europeans (LDlink), such that the lack of association with PV in the German population remains unexplained.

\section{Non-coding RNAs: The new players in complex phe- notypes}

A non-coding RNA (ncRNA) is a functional RNA molecule that is transcribed from DNA but not translated into a polypeptide. NcRNAs are involved in a wide range of biological processes, including gene transcription, posttranscriptional modifications, signal transduction, besides chromatin remodeling and other epigenetic mechanisms. Their deregulation or nucleotide sequence variation may contribute to disease.

For FS in Brazil, 2,080 SNPs located in long ncRNAs (lncRNAs) genes were evaluated in a case-control association study. Six of these polymorphisms possibly have an impact on susceptibility. The variant $r s 7144332 T$ in the lncRNA AL110292.1 showed the most significant association with FS susceptibility. Results for five other lncRNA genes were suggestive of association: $r s 6942557 C$ in LINC01176 and rs $17774133 T$ in LINC01119 were associated with increased risk; rs6095016 $A$ in $\operatorname{lnc}-P R E X 1-7: 1$, rs7195536 $G$ in $A C 009121.1$, and $r s 1542604 T$ in $A C 133785.1$ were associated with decreased disease risk (Lobo-Alves et al., 2019b). The function of these five lncRNA is elusive so far, but it was possible to suggest a functional impact of the SNPs on the lncRNAs structure, expression level, or interaction with microRNAs.

\section{Lack of association with some remarkable candi- dates}

The lymphoid phosphatase LYP (also known as PTPN22 - protein tyrosine phosphatase, nonreceptor-type, 22 ) regulates signal transduction in immune cells. Among its many effects, LYP is a potent negative regulator of T lymphocyte activation (Hill et al., 2002). Genetic variation of PTPN22 (located at 1p13.2) is among the most influential genetic risk factors for ADs outside the MHC (Burn et al., 2011). Increased risk has been associated with variants of PTPN22, notably with allele $T$ of the missense $r s 2476601$ 
$(1858 \mathrm{C}>\mathrm{T})$ single nucleotide polymorphism (SNP) that results in the Arg620Trp amino acid substitution in the first proline-rich motif of the LYP protein (Zheng et al., 2012). The hypothesis that the $r s 2476601 T(620 \mathrm{Trp})$ variant could be a shared risk variant for autoimmune and immunemediated diseases has been raised (Smyth et al., 2004).

Notwithstanding, for PF and PV, there is lack of association with $r s 2476601$. The first study of PF and PV in the Tunisian population (Mejri et al., 2007) provided evidence for no effect of the PTPN22 variant on susceptibility; however, interpretation of the results was hampered because the frequency of allele $T$ was low, impacting the statistical power of the analysis. Later on, in a North American population, the frequency of allele $T$ was higher, of $7.8 \%$ in both the PV patient and control samples, and again no association was seen (Sachdev et al., 2011). For FS, four SNPs (including $r s 2476601)$ in the genomic region 1p13.2, which together tag 28 SNPs on a segment of approximately 312,000 bp encompassing the PTPN22, RSBN1, AL137856.1 genes and the 5' portion of the AP4B1-AS1 gene, were used as markers. No significant association was found. Allele rs $2476601 T$ was observed at the frequency of about $14 \%$ in both the patient and control samples (Lobo-Alves et al., 2019a). So, variants in structural and regulatory sites of $P T P N 22$ and its flanking regions are not susceptibility factors for pemphigus, and it seems settled that the genetic variation of LYP has no impact on pemphigus disease susceptibility.

Most ADs not associated with $r s 2476601$ allele $T$ (LYP 620Trp) manifest in skin, the gastrointestinal tract or in immune privileged sites, leading to the suggestion that the influence of that variant in susceptibility to ADs depends on the affected tissue, and that that the PTPN22 polymorphism is not a shared susceptibility factor to antibody driven ADs (Zheng et al., 2012). This opposition should be explored to deepen the understanding of the mechanisms that differentiate these two groups of ADs.

The $C D 1 D$ gene encodes an MHC class I like glycoprotein $(\mathrm{CD} 1 \mathrm{~d})$ whose primary function is presenting glycolipid antigens to natural killer T (NKT) cells. The CD1D mRNA is overexpressed in T CD4 $4^{+}$lymphocytes of FS patients when compared with healthy individuals (Malheiros et al., 2014). The CDID 3' UTR SNPs rs 16839951 and rs 422236 were not associated with the disease (Cipolla et al., 2016). These results indicate that at least the analyzed genetic variants of CD1d do not contribute to FS susceptibility and that the reason for the previously observed expression difference between the samples of FS patients and unaffected individuals probably is a consequence of the pathogenic process. Also, the KLRD1 rs2537752 and the $N K G 7$ rs3009 were not associated with FS (Cipolla et al., 2016).

Cellular levels of various proapoptotic molecules, including Bax (BCL2-associated x protein) and p53 (tumor protein p53), are increased in pemphigus (Wang et al., 2004). Because apoptosis dysregulation may play a role in pemphigus, genetic variants of the proteins involved in the apoptotic process may participate in the interindividual vari- ation of susceptibility to the disease. Nonetheless, no effect on FS was observed for the $B A X$ gene upstream regulatory region SNP $r_{S} 4645878(-248 \mathrm{G}>\mathrm{A})$, nor for the missense TP53 rs 1042522 (12139C $>$ G, Pro72Arg) SNP (Köhler and Petzl-Erler, 2006).

Associations reported for some cytokine genes were presented above, in a specific topic of this review. Genetic variants of some other cytokine and cytokine receptor genes were analyzed in PV and/or PF: ILIA, ILIB, ILIRI, IL1RA, IL2, IL10, IL12, IL17RA, TNF, IFNG (interferon gamma), LTA (lymphotoxin alpha), MIF (macrophage migration inhibitory factor) and $T G F B 1$ (transforming growth factor beta 1). No convincing associations were seen (Roxo et al., 2003; Pereira et al., 2004; Javor et al., 2010; Saeedi et al., 2013; Ben Jmaa et al., 2018). However, for each of these genes, just one or a few selected SNPs were analyzed.

Lack of association with PF in Tunisia was also observed for variants of the transcription factors RORC (RORGT) and STAT3 which stabilize and maintain Th17 cell function (Ben Jmaa et al., 2018).

\section{Concluding remarks}

Despite the successful identification of several genes and regulatory elements involved in pemphigus pathogenesis, knowledge in that field is still fragmentary, especially for PV. The consensus is that the HLA class II genes have the greatest effect in all forms of pemphigus and all populations. For several of the other genes, replication and validation studies are still lacking. Besides, many real associations certainly were overlooked, simply because the genes were not considered as candidates in published studies. It seemed that genome-wide association studies (GWAS) would permit pinpointing unsuspected non-coding and coding genetic elements. However, pemphigus are mostly rare, and unless very large patient (and control) samples are investigated, only highly significant associations with large effect sizes will be identified. This occurs because very stringent $p$-values are needed to avoid false-positives in GWAS. Consequently, many associations that may be relevant for the disease are missed in such studies. In fact, three recent GWAS of pemphigus in the Han Chinese population confirmed the great effect of HLA, but could not replicate weaker associations (Gao et al., 2018, Sun et al., 2019, Zhang et al., 2019). Moreover, in both the GWAS and the hypothesis-driven candidate gene association studies, the effect of certain variants may remain undetected if specific epistatic interactions between two or more variants are missed because informative tag SNPs of the relevant variant(s) of the additional locus (or loci) are not available or were ignored. Improved analytical approaches for assessing evidence for associations between the disease and clusters of variants rather than just one or a few SNPs, may prove more informative in this regard.

Since the genotype is established before disease onset, it is the genotype that influences the disease, and not contrariwise. Thus, information on pemphigus genetics could support approaches to personalized medicine in the future. Nonetheless, observing an association with an SNP does not 
necessarily imply that the SNP is causal, because of linkage disequilibrium with one to many additional variants. This is a well-known phenomenon that emphasizes the need for fine-mapping and annotating the variants in the genomic region flanking the associated SNP in the particular study population to select the most likely causal SNP(s) for subsequent functional analyses. A critical next step will be to identify the effects of the putative risk variant(s) to understand the disease mechanisms. To achieve this, genetic engineering approaches, such as CRISPR technology-based genome editing, as well as novel techniques to detect DNA-DNA, DNA-RNA, RNA-RNA interactions, and DNA- or RNAprotein interactions combined with the information by expression quantitative trait loci (eQTL) studies will provide insight into the functional impact of non-coding variants on altered cellular phenotypes.

Epigenetic modifications such as DNA methylation and histone modification whose dysregulation can also be implicated in tolerance breakdown and pathogenic autoimmunity add another layer of complexity. Various epigenetic modifications are sensitive to external stimuli and may bridge the gap between the genome and the environment. Therefore, besides mapping epigenetic modifications in health and disease, a better appraisal of the relevant environmental factors is needed. Additionally, key cell types and cell states that may be implicated in pemphigus pathogenesis should be defined. Functional genomic annotations from these cell types and states can then be used to determine candidate genes and regulatory sequences, and the causal variants. Together with longitudinal studies, these approaches may produce crucial insights into how pemphigus develops. The growing understanding of the genetics and epigenetics of autoimmune disease may facilitate early diagnosis, refine the disease phenotypes, and improve therapeutic intervention.

\section{Acknowledgments}

This work was supported by research grants from the Conselho Nacional de Desenvolvimento Científico e Tecnológico (CNPq).

\section{Conflict of Interest}

None to declare.

\section{References}

Abida O, Zitouni M, Kallel-Sellami M, Mahfoudh N, Kammoun A, Ben Ayed M, Masmoudi A, Mokni M, Fezzaa B, Ben Osman A et al. (2009) Tunisian endemic pemphigus foliaceus is associated with the HLA-DR3 gene: anti-desmoglein 1 antibody-positive healthy subjects bear protective alleles. Br J Dermatol 161:522-527.

Ahmed AR, Yunis EJ, Khatri K, Wagner R, Notani G, Awdeh Z and Alper CA (1990) Major histocompatibility complex haplotype studies in Ashkenazi Jewish patients with pemphigus vulgaris. Proc Natl Acad Sci USA 87:7658-7662.

Alpsoy E, Akman-Karakas A and Uzun S (2015) Geographic variations in epidemiology of two autoimmune bullous diseases: pemphigus and bullous pemphigoid. Arch Dermatol Res 307:291-298.

Ameglio F, D'Auria L, Cordiali-Fei P, Trento E, D'Agosto G, Mastroianni A, Giannetti A and Giacalone B (1999) Antiintercellular substance antibody log titres are correlated with serum concentrations of interleukin-6, interleukin- 15 and tumor necrosis factor-alpha in patients with pemphigus vulgaris relationships with peripheral blood neutrophil counts, disease severity and duration and patients' age. J Biol Regul Homeost Agents 13:220-224.

Aoki V, Millikan RC, Rivitti EA, Hans-Filho G, Eaton DP, Warren SJ, Li N, Hilario-Vargas J, Hoffmann RG, Diaz LA et al. (2004) Environmental risk factors in endemic pemphigus foliaceus (fogo selvagem). J Investig Dermatol Symp Proc 9:34-40.

Asashima N, Fujimoto M, Watanabe R, Nakashima H, Yazawa N, Okochi H and Tamaki K (2006) Serum levels of BAFF are increased in bullous pemphigoid but not in pemphigus vulgaris. Br J Dermatol 155:330-336.

Augusto DG, Lobo-Alves SC, Melo MF, Pereira NF and PetzlErler ML (2012) Activating KIR and HLA Bw4 ligands are associated to decreased susceptibility to pemphigus foliaceus, an autoimmune blistering skin disease. PLoS One 7:e39991.

Augusto DG, O'Connor GM, Lobo-Alves SC, Bass S, Martin MP, Carrington M, McVicar DW and Petzl-Erler ML (2015) Pemphigus is associated with KIR3DL2 expression levels and provides evidence that KIR3DL2 may bind HLA-A3 and A11 in vivo. Eur J Immunol 45:2052-2060.

Augusto DG and Petzl-Erler ML (2015) KIR and HLA under pressure: evidences of coevolution across worldwide populations. Hum Genet 134:929-940.

Ayed MB, Martel P, Zitouni M, Gilbert D, Turki H, Mokni M, Osman AB, Kamoun MR, Zahaf A, Makni S et al. (2002) Tunisian endemic pemphigus foliaceus is associated with desmoglein 1 gene polymorphism. Genes Immun Sep 3:378-9.

Barrow AD and Trowsdale J (2008) The extended human leukocyte receptor complex: diverse ways of modulating immune responses. Immunol Rev 224:98-123.

Bastuji-Garin S, Souissi R, Blum L, Turki H, Nouira R, Jomaa B, Zahaf A, Ben Osman A, Mokhtar I, Fazaa B et al. (1995) Comparative epidemiology of pemphigus in Tunisia and France: unusual incidence of pemphigus foliaceus in young Tunisian women. J Invest Dermatol 104:302-305.

Ben Jmaa M, Abida O, Bahloul E, Toumi A, Khlif S, Fakhfakh R, Elloumi N, Sellami K, Masmoudi A, Turki H et al. (2017) Role of FOXP3 gene polymorphism in the susceptibility to Tunisian endemic Pemphigus Foliaceus. Immunol Lett 184:105-111.

Ben Jmaa M, Abida O, Fakhfakh R, Bahloul E, Sellami K, Gaddour L, Elloumi N, Ben Ayed M, Masmoudi A, Dhouib M et al. (2018) Involvement of the IL23/Th17 pathway in the pathogenesis of Tunisian pemphigus foliaceus. Mediators Inflamm 2018:8206983.

Bhanusali DG, Sachdev A, Rahmanian A, Gerlach JA, Tong JC, Seiffert-Sinha K and Sinha AA (2013) HLA-E*0103X is associated with susceptibility to pemphigus vulgaris. Exp Dermatol 22:108-112.

Braun-Prado K and Petzl-Erler ML (2007) Programmed cell death 1 gene (PDCD1) polymorphism and pemphigus foliaceus (fogo selvagem) disease susceptibility. Genet Mol Biol 30:314-321.

Brochado MJ, Nascimento DF, Campos W, Deghaide NH, Donadi EA and Roselino AM (2016) Differential HLA class I and class II associations in pemphigus foliaceus and pemphigus 
vulgaris patients from a prevalent Southeastern Brazilian region. J Autoimmun 72:19-24.

Bumiller-Bini V, Cipolla GA, Almeida RC, Petzl-Erler ML, Augusto DG and Boldt ABW (2018) Sparking fire under the skin? answers from the association of complement genes with pemphigus foliaceus. Front Immunol 9:695.

Bumiller-Bini V, Cipolla GA, Spadoni M, Augusto DG, Petzl-Erler ML, Beltrame MH and Boldt ABW (2019) Condemned or not to die? Gene polymorphisms altering susceptibility to cell death in pemphigus foliaceus. Front Immunol 10:2416.

Burn GL, Svensson L, Sanchez-Blanco C, Saini M and Cope AP (2011) Why is PTPN22 a good candidate susceptibility gene for autoimmune disease? FEBS Lett 585:3689-3698.

Camargo CM, Augusto DG and Petzl-Erler ML (2016) Differential gene expression levels might explain association of LAIR2 polymorphisms with pemphigus. Hum Genet 135:233-244.

Capon F, Bharkhada J, Cochrane NE, Mortimer NJ, Setterfield JF, Reynaert S, Black MM, Vaughan RW, Trembath RC and Harman KE (2006) Evidence of an association between desmoglein 3 haplotypes and pemphigus vulgaris. Br J Dermatol 154:67-71.

Capon F, Boulding H, Quaranta M, Mortimer NJ, Setterfield JF, Black MM, Trembath RC and Harman KE (2009) Genetic analysis of desmoglein 3 (DSG3) sequence variants in patients with pemphigus vulgaris. Br J Dermatol 161:1403-1405.

Caproni M, Antiga E, Torchia D, Volpi W, del Bianco E, Cappetti A, Feliciani C and Fabbri P (2007) The CD40/CD40 ligand system is involved in the pathogenesis of pemphigus. Clin Immunol 124:22-25.

Carcassi C, Cottoni F, Floris L, Vacca A, Mulargia M, Arras M, Boero R, La Nasa G, Ledda A, Pizzati A et al. (1996) HLA haplotypes and class II molecular alleles in Sardinian and Italian patients with pemphigus vulgaris. Tissue Antigens 48:662-667.

Carithers LJ, Ardlie K, Barcus M, Branton PA, Britton A, Buia SA, Compton CC, DeLuca DS, Peter-Demchok J, Gelfand ET et al. (2015) A novel approach to high-quality postmortem tissue procurement: the gtex project. Biopreserv Biobank 13:311-319.

Cerna M, Fernandez-Viña M, Friedman H, Moraes JR, Moraes ME, Diaz L and Stastny P (1993) Genetic markers for susceptibility to endemic Brazilian pemphigus foliaceus (fogo selvagem) in Xavante Indians. Tissue Antigens 42:138-140.

Chandra A, Ray A, Senapati S and Chatterjee R (2015) Genetic and epigenetic basis of psoriasis pathogenesis. Mol Immunol 64:313-323.

Chiossi MP and Roselino AM (2001) Endemic Pemphigus foliaceus ("Fogo selvagem"): a series from the northeastern region of the State of São Paulo, Brazil, 1973-1998. Rev Inst Med Trop Sao Paulo 43:59-62.

Chiossi MP, Costa RS and Roselino AM (2004) Dermal dendritic cell number correlates with serum autoantibody titers in Brazilian pemphigus foliaceus patients. Braz J Med Biol Res 37:337-341.

Chriguer RS, Roselino AM and de Castro M (2012) Glucocorticoid sensitivity and proinflammatory cytokines pattern in pemphigus. J Clin Immunol 32:786-793.

Cipolla GA, Park JK, Oliveira LA, Lobo-Alves SC, Almeida RC, Farias TD, Lemos DS, Malheiros D, Lavker RM and PetzlErler ML (2016) A 3'UTR polymorphism marks differential KLRG1 mRNA levels through disruption of a miR-584-5p binding site and associates with pemphigus foliaceus susceptibility. Biochim Biophys Acta 1859:1306-1313.

Coyle AJ, Lehar S, Lloyd C, Tian J, Delaney T, Manning S, Nguyen T, Burwell T, Schneider H, Gonzalo JA et al. (2000) The
CD28-related molecule ICOS is required for effective T celldependent immune responses. Immunity 13:95-105.

Cunningham F, Achuthan P, Akanni W, Allen J, Amode MR, Armean IM, Bennett R, Bhai J, Billis K, Boddu S et al. (2019) Ensembl 2019. Nucleic Acids Res 47:D745-D751.

Dalla-Costa R, Pincerati MR, Beltrame MH, Malheiros D and Petzl-Erler ML (2010) Polymorphisms in the 2q33 and $3 q 21$ chromosome regions including T-cell coreceptor and ligand genes may influence susceptibility to pemphigus foliaceus. Hum Immunol 71:809-817.

de Jong H, Koffeman EC, Meerding JM, Scholman RC, Wieten L, de Jager W, Klein M, Otten H, van Wijk F, van der Zee R et al. (2014) T cell recognition of naturally presented epitopes of self-heat shock protein 70. Cell Stress Chaperones 19:569-578.

Donadi EA, Castelli EC, Arnaiz-Villena A, Roger M, Rey D and Moreau P (2011) Implications of the polymorphism of HLA$\mathrm{G}$ on its function, regulation, evolution and disease association. Cell Mol Life Sci 68:369-395.

Etesami I, Seirafi H, Ghandi N, Salmani H, Arabpour M, Nasrollahzadeh A, Teimourpour A, Daneshpazhooh M and Keramatipour M (2018) The association between ST18 gene polymorphism and severe pemphigus disease among Iranian population. Exp Dermatol 27:1395-1398.

Farias TDJ, Augusto DG, Almeida RC, Malheiros D and PetzlErler ML (2019) Screening the full leucocyte receptor complex genomic region revealed associations with pemphigus that might be explained by gene regulation. Immunology 156:86-93.

Firooz A, Mazhar A and Ahmed AR (1994) Prevalence of autoimmune diseases in the family members of patients with pemphigus vulgaris. J Am Acad Dermatol 31:434-437.

Fishman D, Faulds G, Jeffery R, Mohamed-Ali V, Yudkin JS, Humphries S and Woo P (1998) The effect of novel polymorphisms in the interleukin-6 (IL-6) gene on IL-6 transcription and plasma IL-6 levels, and an association with systemic-onset juvenile chronic arthritis. J Clin Invest 102:1369-1376.

Flores G, Culton DA, Prisayanh P, Qaqish BF, James K, Maldonado M, Aoki V, Hans-Filho G, Rivitti EA and Diaz LA (2012) IgG autoantibody response against keratinocyte cadherins in endemic pemphigus foliaceus (fogo selvagem). J Invest Dermatol 132:2573-2580.

Galluzzi L, Vitale I, Aaronson SA, Abrams JM, Adam D, Agostinis, P, Alnemri ES, Altucci L, Amelio I, Andrews DW et al. (2018) Molecular mechanisms of cell death: Recommendations of the nomenclature committee on cell death 2018. Cell Death Differ 25:486-541.

Gao J, Zhu C, Zhang Y, Sheng Y, Yang F, Wang W, Qian W, Chen S, Zhu Q, Zuo X et al. (2018) Association study and finemapping major histocompatibility complex analysis of pemphigus vulgaris in a Han Chinese population. J Invest Dermatol 138:2307-2314.

Gazit E, Slomov Y, Goldberg I, Brenner S and Loewenthal R (2004) HLA-G is associated with pemphigus vulgaris in Jewish patients. Hum Immunol 65:39-46.

Gianchecchi E, Delfino DV and Fierabracci A (2018) NK cells in autoimmune diseases: linking innate and adaptive immune responses. Autoimmun Rev 17:142-154.

Gniadecki R, Jemec GB, Thomsen BM and Hansen M (1998) Relationship between keratinocyte adhesion and death: anoikis in acantholytic diseases. Arch Dermatol Res 290:528-532.

Gonzalez-Galarza FF, McCabe A, Melo Dos Santos EJ, Takeshita L, Ghattaoraya G, Jones AR and Middleton D (2018) Allele Frequency Net Database. Methods Mol Biol 1802:49-62. 
Goronzy JJ and Weyand CM (2008) T-cell co-stimulatory pathways in autoimmunity. Arthritis Res Ther 10 Suppl 1:S3.

Gupta VK, Kelbel TE, Nguyen D, Melonakos KC, Murrell DF, Xie Y, Mullard A, Reed PL, Seiffert-Sinha K and Sinha AA (2011) A globally available internet-based patient survey of pemphigus vulgaris: epidemiology and disease characteristics. Dermatol Clin 29:393-404.

Haase O, Alneebari R, Eldarouti MA, Abd El Hady M, Dorgham D, El-Nabarawy E, El Din Mahmoud SB, Mosaad El Sayed H, Darwish M, Abbas F et al. (2015) Association with HLADRB1 in Egyptian and German pemphigus vulgaris patients. Tissue Antigens 85:283-286.

Hajishengallis G, Reis ES, Mastellos DC, Ricklin D and Lambris JD (2017) Novel mechanisms and functions of complement. Nat Immunol 18:1288-1298.

Hans-Filho G, Aoki V, Bittner NRH and Bittner GC (2018) Fogo selvagem: endemic pemphigus foliaceus. An Bras Dermatol 93:638-650

Hans-Filho G, Aoki V, Rivitti E, Eaton DP, Lin MS and Diaz LA (1999) Endemic pemphigus foliaceus (fogo selvagem) 1998. The Cooperative Group on Fogo Selvagem Research. Clin Dermatol 17:225-235.

He JJ, Zhang W, He YM, Wang W, Han ZD, Chen NY, Zhu FM, Lv HJ and Yan LX (2012) [Analysis of allele frequencies of HLA-DRB1*12:01:01G and HLA-DRB1*14:01:01G groups]. Zhonghua Yi Xue Yi Chuan Xue Za Zhi 29:87-90.

Hervé M, Isnardi I, Ng YS, Bussel JB, Ochs HD, CunninghamRundles C and Meffre E (2007) CD40 ligand and MHC class II expression are essential for human peripheral B cell tolerance. J Exp Med 204:1583-1593.

Hill RJ, Zozulya S, Lu YL, Ward K, Gishizky M and Jallal B (2002) The lymphoid protein tyrosine phosphatase Lyp interacts with the adaptor molecule Grb2 and functions as a negative regulator of T-cell activation. Exp Hematol 30:237-244.

Hromas R, Collins SJ, Hickstein D, Raskind W, Deaven LL, O'Hara P, Hagen FS and Kaushansky K (1991) A retinoic acid-responsive human zinc finger gene, MZF-1, preferentially expressed in myeloid cells. J Biol Chem 266:14183-14187.

Hung KH, Woo YH, Lin IY, Liu CH, Wang LC, Chen HY, Chiang $\mathrm{BL}$ and Lin KI (2018) The KDM4A/KDM4C/NF- $\kappa \mathrm{B}$ and WDR5 epigenetic cascade regulates the activation of $\mathrm{B}$ cells. Nucleic Acids Res 46:5547-5560.

Iwaszko M, Swierkot J, Kolossa K, Jeka S, Wiland P and BoguniaKubik K (2015) Polymorphisms within the human leucocyte antigen-E gene and their associations with susceptibility to rheumatoid arthritis as well as clinical outcome of anti-tumour necrosis factor therapy. Clin Exp Immunol 182:270-277.

Jacobson EM, Concepcion E, Oashi T and Tomer Y (2005) A Graves' disease-associated Kozak sequence singlenucleotide polymorphism enhances the efficiency of CD40 gene translation: a case for translational pathophysiology. Endocrinology 146:2684-2691.

Janse IC, Van Der Wier G, Jonkman MF, Pas HH and Diercks GF (2014) No evidence of apoptotic cells in pemphigus acantholysis. J Invest Dermatol 134:2039-2041.

Javor J, Chmurova N, Parnicka Z, Ferencik S, Grosse-Wilde H, Buc M and Svecova D (2010) TNF-alpha and IL-10 gene polymorphisms show a weak association with pemphigus vulgaris in the Slovak population. J Eur Acad Dermatol Venereol 24:65-68.

Kalantari-Dehaghi M, Anhalt GJ, Camilleri MJ, Chernyavsky AI, Chun S, Felgner PL, Jasinskas A, Leiferman KM, Liang L,
Marchenko S et al. (2013) Pemphigus vulgaris autoantibody profiling by proteomic technique. PLoS One 8:e57587.

Kasperkiewicz M, Ellebrecht CT, Takahashi H, Yamagami J, Zillikens D, Payne AS and Amagai M (2017) Pemphigus. Nat Rev Dis Primers 11:17026.

Kawasaki A, Tsuchiya N, Fukazawa T, Hashimoto H and Tokunaga K (2002) Analysis on the association of human BLYS (BAFF, TNFSF13B) polymorphisms with systemic lupus erythematosus and rheumatoid arthritis. Genes Immun 3:424-429.

Keir ME, Francisco LM and Sharpe AH (2007) PD-1 and its ligands in T-cell immunity. Curr Opin Immunol 19:309-314.

Köhler KF and Petzl-Erler ML (2006) No evidence for association of the TP53 12139 and the BAX-248 polymorphisms with endemic pemphigus foliaceus (fogo selvagem). Int J Immunogenet 33:141-144.

Kulkarni S, Martin MP and Carrington M (2008) The Yin and Yang of HLA and KIR in human disease. Semin Immunol 20:343-352.

Kuroki K, Tsuchiya N, Tsao BP, Grossman JM, Fukazawa T, Hagiwara K, Kano H, Takazoe M, Iwata T, Hashimoto H et al. (2002) Polymorphisms of human CD19 gene: possible association with susceptibility to systemic lupus erythematosus in Japanese. Genes Immun 3 Suppl 1:S21-30.

Kurreeman FA, Goulielmos GN, Alizadeh BZ, Rueda B, Houwing-Duistermaat J, Sanchez E, Bevova M, Radstake TR, Vonk MC, Galanakis E et al. (2010) The TRAF1-C5 region on chromosome $9 \mathrm{q} 33$ is associated with multiple autoimmune diseases. Ann Rheum Dis 69:696-699.

Lauterbach N, Wieten L, Popeijus HE, Voorter CE and Tilanus MG (2015) HLA-E regulates NKG2C+ natural killer cell function through presentation of a restricted peptide repertoire. Hum Immunol 76:578-586.

Lee HE, Berkowitz P, Jolly PS, Diaz LA, Chua MP and Rubenstein DS (2009) Biphasic activation of p38MAPK suggests that apoptosis is a downstream event in pemphigus acantholysis. $\mathrm{J}$ Biol Chem 284:12524-12532.

Lee KW and Jung YA (2009) Additional sequence analysis outside exon 2 clarifies DRB1*12 and DRB1*14 allelic frequencies in Koreans. Hum Immunol 70:464-467.

Lee HJ, Li CW, Hammerstad SS, Stefan M and Tomer Y (2015a) Immunogenetics of autoimmune thyroid diseases: a comprehensive review. J Autoimmun 64:82-90.

Lee YH, Bae SC, Choi SJ, Ji JD and Song GG (2015b) Associations between the functional CD40 rs4810485 G/T polymorphism and susceptibility to rheumatoid arthritis and systemic lupus erythematosus: a meta-analysis. Lupus 24:1177-1183.

Li YR, Li J, Zhao SD, Bradfield JP, Mentch FD, Maggadottir SM, Hou C, Abrams DJ, Chang D, Gao F et al. (2015) Metaanalysis of shared genetic architecture across ten pediatric autoimmune diseases. Nat Med 21:1018-1027.

Ligers A, Teleshova N, Masterman T, Huang WX and Hillert J (2001) CTLA-4 gene expression is influenced by promoter and exon 1 polymorphisms. Genes Immun 2:145-152.

Liu Z, Zeng W, Huang X, Wang S, Zheng J, Pan M and Wang Y (2017) Peripheral CD19(hi) B cells exhibit activated phenotype and functionality in promoting $\operatorname{IgG}$ and $\operatorname{IgM}$ production in human autoimmune diseases. Sci Rep 7:13921.

Lobo-Alves SC, Oliveira LA and Petzl-Erler ML (2019a) Region 1p13.2 including the RSBN1, PTPN22, AP4B1 and long non-coding RNA genes does not bear risk factors for endemic pemphigus foliaceus (fogo selvagem). Int J Immunogenet 46:139-145

Lobo-Alves SC, Augusto DG, Magalhães WCS, Tarazona-Santos E, Lima-Costa MF, Barreto ML, Horta BL, Almeida RC and 
Petzl-Erler ML (2019b) Long noncoding RNA polymorphisms influence susceptibility to endemic pemphigus foliaceus. Br J Dermatol 181:324-331.

Lombardi C, Borges PC, Chaul A, Sampaio SA, Rivitti EA, Friedman H, Martins CR, Sanches Júnior JA, Cunha PR, Hoffmann RG et al. (1992) Environmental risk factors in endemic pemphigus foliaceus (Fogo selvagem). "The Cooperative Group on Fogo Selvagem Research". J Invest Dermatol 98:847-850.

Malheiros D, Panepucci RA, Roselino AM, Araújo AG, Zago MA and Petzl-Erler ML (2014) Genome-wide gene expression profiling reveals unsuspected molecular alterations in pemphigus foliaceus. Immunology 143:381-395.

Malheiros D and Petzl-Erler ML (2009) Individual and epistatic effects of genetic polymorphisms of B-cell co-stimulatory molecules on susceptibility to pemphigus foliaceus. Genes Immun 10:547-558.

Martel P, Gilbert D, Drouot L, Prost C, Raux G, Delaporte E, Joly P and Tron F (2001) A polymorphic variant of the gene coding desmoglein 1, the target autoantigen of pemphigus foliaceus, is associated with the disease. Genes Immun 2:41-43.

Martel P, Gilbert D, Busson M, Loiseau P, Lepage V, Drouot L, Delaporte E, Prost C, Joly P, Charron D et al. (2002) Epistasis between DSG1 and HLA class II genes in pemphigus foliaceus. Genes Immun 3:205-210.

Mejri K, Kallel-Sellami M, Petit-Teixeira E, Abida O, Mbarek H, Zitouni M, Ben Ayed M, Teixeira VH, Mokni M, Fazza B et al. (2007) PTPN22 R620W polymorphism is not associated with pemphigus. Br J Dermatol 157:1068-1069.

Mejri K, Mbarek H, Kallel-Sellami M, Petit-Teixeira E, Zerzeri Y, Abida O, Zitouni M, Ben Ayed M, Mokni M, Fezza B et al. (2009) TRAF1/C5 polymorphism is not associated with pemphigus. Br J Dermatol 160:1348-1350.

Mellins ED and Stern LJ (2013) HLA-DM and HLA-DO, key regulators of MHC-II processing and presentation. Curr Opin Immunol 26:115-122.

Meyaard L (2008) The inhibitory collagen receptor LAIR-1 (CD305). J Leukoc Biol 83:799-803.

Mihara M, Hashizume M, Yoshida H, Suzuki M and Shiina M (2012) IL-6/IL-6 receptor system and its role in physiological and pathological conditions. Clin Sci (Lond) 122:143-159.

Moraes JR, Moraes ME, Fernandez-Vina M, Diaz LA, Friedman H, Campbell IT, Alvarez RR, Sampaio SA, Rivitti EA and Stastny P (1991) HLA antigens and risk for development of pemphigus foliaceus (fogo selvagem) in endemic areas of Brazil. Immunogenetics 33:388-391.

Moraes ME, Fernandez-Vina M, Lazaro A, Diaz LA, Filho GH, Friedman H, Rivitti E, Aoki V, Stastny P and Moraes JR (1997) An epitope in the third hypervariable region of the DRB1 gene is involved in the susceptibility to endemic pemphigus foliaceus (fogo selvagem) in three different Brazilian populations. Tissue Antigens 49:35-40.

Narbutt J, Lesiak A, Klich I, Torzecka JD, Sysa-Jedrzejowska A and Mlynarski W (2010) ICOS gene polymorphism may be associated with pemphigus. J Cutan Med Surg 14:291-297.

Nielsen HM and Tost J (2013) Epigenetic changes in inflammatory and autoimmune diseases. Subcell Biochem 61:455-478.

Niizeki H, Kumagai S, Kanagawa S, Amagai M, Yamashina Y, Asada H, Nishikawa T and Miyagawa S (2004) Exclusion of the TAP1 and TAP2 genes within the HLA class II region as candidate susceptibility genes to pemphigus in the Japanese population. J Dermatol Sci 36:122-124.

O'Callaghan CA and Bell JI (1998) Structure and function of the human MHC class Ib molecules HLA-E, HLA-F and HLA-G. Immunol Rev 163:129-138.
O'Rielly DD and Rahman P (2015) Genetic, epigenetic and pharmacogenetic aspects of psoriasis and psoriatic arthritis. Rheum Dis Clin North Am 41:623-642.

Oda JM, Hirata BK, Guembarovski RL and Watanabe MA (2013) Genetic polymorphism in FOXP3 gene: imbalance in regulatory T-cell role and development of human diseases. J Genet 92:163-171.

Oliveira LC, Kretzschmar GC, Santos ACM, Camargo CM, Nisihara RM, Farias TDJ, Franke A, Wittig M, Schmidt E, Busch H et al. (2019) Complement receptor 1 (CR1, CD35) polymorphisms and soluble CR1: A proposed anti-inflammatory role to quench the fire of "fogo selvagem" pemphigus foliaceus. Front Immunol 10:2585.

Ooi JD, Petersen J, Tan YH, Huynh M, Willett ZJ, Ramarathinam SH, Eggenhuizen PJ, Loh KL, Watson KA, Gan PY et al. (2017) Dominant protection from HLA-linked autoimmunity by antigen-specific regulatory T cells. Nature 545:243-247.

Párnická Z, vecová D, Javor J, Shawkatová I and Buc M (2013) High susceptibility to pemphigus vulgaris due to HLADRB1*14:54 in the Slovak population. Int J Immunogenet 40:471-475.

Pavoni DP, Roxo VM, Marquart Filho A and Petzl-Erler ML (2003) Dissecting the associations of endemic pemphigus foliaceus (fogo selvagem) with HLA-DRB1 alleles and genotypes. Genes Immun 4:110-116.

Pereira NF, Hansen JA, Lin MT, Roxo VM, Braun K and PetzlErler ML (2004) Cytokine gene polymorphisms in endemic pemphigus foliaceus: a possible role for IL6 variants. Cytokine 28:233-241.

Petzl-Erler ML and Malheiros D (2005) Pemphigus foliaceus and desmoglein 1 gene polymorphism: is there any relationship? J Autoimmun 25:121-125.

Petzl-Erler ML and Santamaria J (1989) Are HLA class II genes controlling susceptibility and resistance to Brazilian pemphigus foliaceus (fogo selvagem)? Tissue Antigens 33:408-414.

Picascia A, Grimaldi V, Pignalosa O, De Pascale MR, Schiano C and Napoli C (2015) Epigenetic control of autoimmune diseases: from bench to bedside. Clin Immunol 157:1-15.

Piovezan BZ and Petzl-Erler ML (2013) Both qualitative and quantitative genetic variation of MHC class II molecules may influence susceptibility to autoimmune diseases: the case of endemic pemphigus foliaceus. Hum Immunol 74:1134-1140.

Qian Y, Culton DA, Jeong JS, Trupiano N, Valenzuela JG and Diaz LA (2016) Non-infectious environmental antigens as a trigger for the initiation of an autoimmune skin disease. Autoimmun Rev 15:923-930.

Recke A, Vidarsson G, Ludwig RJ, Freitag M, Möller S, Vonthein R, Schellenberger J, Haase O, Görg S, Nebel A et al. (2015) Allelic and copy-number variations of Fc $\gamma$ Rs affect granulocyte function and susceptibility for autoimmune blistering diseases. J Autoimmun 61:36-44.

Rivera-Chavez FA, Peters-Hybki DL, Barber RC and O'Keefe GE (2003) Interleukin-6 promoter haplotypes and interleukin-6 cytokine responses. Shock 20:218-223.

Rodrigues DBR, Pereira SAL, Reis MA, Adad SJ, Caixeta JE, Chiba AM, Sousa RA and Rodrigues V Jr (2009) In situ detection of inflammatory cytokines and apoptosis in pemphigus foliaceus patients. Arch Pathol Lab Med 133:97-100.

Roxo VM, Pereira NF, Pavoni DP, Lin MT, Hansen JA, O Poersch C, Filho AM and Petzl-Erler ML (2003) Polymorphisms within the tumor necrosis factor and lymphotoxin-alpha genes and endemic pemphigus foliaceus - are there any associations? Tissue Antigens 62:394-400. 
Ruocco V, Ruocco E, Lo Schiavo A, Brunetti G, Guerrera LP and Wolf R (2013) Pemphigus: etiology, pathogenesis, and inducing or triggering factors: facts and controversies. Clin Dermatol 31:374-381.

Sachdev A, Bhanusali DG, Patterson KC, Zamora MB, Ghuman A, Gerlach JA and Sinha AA (2011) PTPN22 1858T is not a risk factor for North American pemphigus vulgaris. Exp Dermatol 20:514-519.

Saeedi M, Amoli MM, Robati RM, Sayahpour F, Namazi N and Toossi P (2013) Macrophage migration inhibitory factor gene polymorphism is not associated with pemphigus vulgaris in Iranian patients. J Eur Acad Dermatol Venereol 27:1127-1131.

Saha M, Harman K, Mortimer NJ, Binda V, Black MM, Kondeatis E, Vaughan R and Groves RW (2010) Pemphigus vulgaris in White Europeans is linked with HLA Class II allele HLA DRB1*1454 but not DRB1*1401. J Invest Dermatol 130:311-314.

Sajda T, Hazelton J, Patel M, Seiffert-Sinha K, Steinman L, Robinson W, Haab BB and Sinha AA (2016) Multiplexed autoantigen microarrays identify HLA as a key driver of antidesmoglein and -non-desmoglein reactivities in pemphigus. Proc Natl Acad Sci USA 113:1859-1864.

Salviano-Silva A, Petzl-Erler ML and Boldt ABW (2017) CD59 polymorphisms are associated with gene expression and different sexual susceptibility to pemphigus foliaceus. Autoimmunity 50:377-385.

Sarig O, Bercovici S, Zoller L, Goldberg I, Indelman M, Nahum S, Israeli S, Sagiv N, Martinez de Morentin H, Katz O et al. (2012) Population-specific association between a polymorphic variant in ST18, encoding a pro-apoptotic molecule, and pemphigus vulgaris. J Invest Dermatol 132:1798-1805.

Schmidt E, Gutberlet J, Siegmund D, Berg D, Wajant H and Waschke $\mathrm{J}$ (2009) Apoptosis is not required for acantholysis in pemphigus vulgaris. Amer J Physiol Cell Physiol 296:C162-172.

Shams S, Amirzargar AA, Yousefi M, Rezaei N, Solgi G, Khosravi F, Ansaripour B, Moradi B and Nikbin B (2009) HLA class II (DRB, DQA1 and DQB1) allele and haplotype frequencies in the patients with pemphigus vulgaris. J Clin Immunol 29:175-179.

Slomov E, Loewenthal R, Korostishevsky M, Goldberg I, Brenner S and Gazit E (2005) Pemphigus vulgaris is associated with the transporter associated with antigen processing (TAP) system. Hum Immunol 66:1213-1222.

Smyth D, Cooper JD, Collins JE, Heward JM, Franklyn JA, Howson JM, Vella A, Nutland S, Rance HE, Maier L et al. (2004) Replication of an association between the lymphoid tyrosine phosphatase locus (LYP/PTPN22) with type 1 diabetes, and evidence for its role as a general autoimmunity locus. Diabetes 53:3020-3023.

Sokol E, Kramer D, Diercks GF, Kuipers J, Jonkman MF, Pas HH and Giepmans BNG (2015) Large-scale electron microscopy maps of patient skin and mucosa provide insight into pathogenesis of blistering diseases. J Invest Dermatol 135:1763-1770.

Spadoni MB, Bumiller-Bini V, Petzl-Erler ML, Augusto DG and Boldt ABW (2020) First glimpse of epigenetic effects on pemphigus foliaceus. J Invest Dermatol 140:488-491.

Steri M, Orrù V, Idda ML, Pitzalis M, Pala M, Zara I, Sidore C, Fà̀ V, Floris M, Deiana M et al. (2017) Overexpression of the cytokine BAFF and autoimmunity risk. N Engl J Med 376:1615-1626.

Sun Y, Liu H, Yang B, Wang C, Foo JN, Bao F, Irwanto A, Yu G, Fu X, Wang Z et al. (2019) Investigation of the predisposing factor of pemphigus and its clinical subtype through a genome-wide association and next generation sequence analysis. J Eur Acad Dermatol Venereol 33:410-415.
Swanberg M, Lidman O, Padyukov L, Eriksson P, Akesson E, Jagodic M, Lobell A, Khademi M, Börjesson O, Lindgren $\mathrm{CM}$ et al. (2005) MHC2TA is associated with differential MHC molecule expression and susceptibility to rheumatoid arthritis, multiple sclerosis and myocardial infarction. Nat Genet 37:486-494.

Takahashi H, Amagai M, Tanikawa A, Suzuki S, Ikeda Y, Nishikawa T, Kawakami Y and Kuwana M (2007) T helper type 2-biased natural killer cell phenotype in patients with pemphigus vulgaris. J Invest Dermatol 127:324-330.

Timóteo RP, Silva MV, Miguel CB, Silva DA, Catarino JD, Rodrigues Junior V, Sales-Campos H and Freire Oliveira CJ (2017a) Th1/Th17-Related cytokines and chemokines and their implications in the pathogenesis of pemphigus vulgaris. Mediators Inflamm 2017:7151285.

Timóteo RP, Silva MV, Silva DAA, Catarino JDS, Alves FHC, Rodrigues Júnior V, Roselino AM, Sales-Campos H and Oliveira CJF (2017b) Cytokine and chemokines alterations in the endemic form of pemphigus foliaceus (Fogo Selvagem). Front Immunol 8:978.

Toumi A, Abida O, Ben-Ayed M, Masmoudi A, Turki H and Masmoudi H (2013) Cytokine gene polymorphisms in Tunisian endemic pemphigus foliaceus: a possible role of IL-4 variants. Hum Immunol 74:658-665.

Toumi A, Abida O, Ben-Ayed M, Masmoudi A, Turki H and Masmoudi H (2015) Is there any relationship between polymorphism of heat shock protein 70 genes and Pemphigus foliaceus? Immunol Lett 164:94-99.

Tsuneto LT, Probst CM, Hutz MH, Salzano FM, Rodriguez-Delfin LA, Zago MA, Hill K, Hurtado AM, Ribeiro-dos-Santos AK and Petzl-Erler ML (2003) HLA class II diversity in seven Amerindian populations. Clues about the origins of the Aché. Tissue Antigens 62:512-526.

van Zelm MC, Bartol SJ, Driessen GJ, Mascart F, Reisli I, Franco JL, Wolska-Kusnierz B, Kanegane H, Boon L, van Dongen JJ et al. (2014) Human CD19 and CD40L deficiencies impair antibody selection and differentially affect somatic hypermutation. J Allergy Clin Immunol 134:135-144.

Veldman C, Höhne A, Dieckmann D, Schuler G and Hertl M (2004) Type I regulatory T cells specific for desmoglein 3 are more frequently detected in healthy individuals than in patients with pemphigus vulgaris. J Immunol 172:6468-6475.

Vidan-Jeras B, Buhler S, Dubois V, Grubic Z, Ivanova M, Jaatinen T, Ligeiro D, Lokki ML, Papasteriades C, Poli F et al. (2014) Resolution of HLA-B*44:02:01G, -DRB1*14:01:01G and -DQB1*03:01:01G reveals a high allelic variability among 12 European populations. Tissue Antigens 84:459-464.

Vincent FB, Saulep-Easton D, Figgett WA, Fairfax KA and Mackay F (2013) The BAFF/APRIL system: emerging functions beyond $\mathrm{B}$ cell biology and autoimmunity. Cytokine Growth Factor Rev 24:203-215.

Vodo D, Sarig O, Geller S, Ben-Asher E, Olender T, Bochner R, Goldberg I, Nosgorodsky J, Alkelai A, Tatarskyy P et al. (2016) Identification of a Functional Risk Variant for Pemphigus Vulgaris in the ST18 Gene. PLoS Genet 12:e1006008.

Wang XB, Zhao X, Giscombe R and Lefvert AK (2002) A CTLA-4 gene polymorphism at position -318 in the promoter region affects the expression of protein. Genes Immun 3:233-234.

Wang X, Brégégère F, Frusic-Zlotkin M, Feinmesser M, Michel B and Milner Y (2004) Possible apoptotic mechanism in epidermal cell acantholysis induced by pemphigus vulgaris autoimmunoglobulins. Apoptosis 9:131-143.

Wang XB, Pirskanen R, Giscombe R and Lefvert AK (2008) Two SNPs in the promoter region of the CTLA-4 gene affect bind- 
ing of transcription factors and are associated with human myasthenia gravis. J Intern Med 263:61-69.

Yamashina Y, Miyagawa S, Kawatsu T, Iida T, Higashimine I, Shirai T and Kaneshige T (1998) Polymorphisms of HLA class II genes in Japanese patients with pemphigus vulgaris. Tissue Antigens 52:74-77.

Yang N, Ray DW and Matthews LC (2012) Current concepts in glucocorticoid resistance. Steroids 77:1041-1049.

Yanovsky RL, McLeod M and Ahmed AR (2019) Treatment of pemphigus vulgaris: part 2 - emerging therapies. Expert Rev Clin Immunol 15:1061-1071.

Yari F, Zavaran Hosseini A, Nemat Gorgani M, Khorramizadeh MR, Mansouri P and Kazemnejad A (2008) Expression of HLA-G in the skin of patients with pemphigus vulgaris. Iran J Allergy Asthma Immunol 7:7-12.

Yue Z, Fu X, Chen M, Wang Z, Wang C, Yang B, Zhou G, Liu H and Zhang F (2014) Lack of association between the single nucleotide polymorphism of ST18 and pemphigus in Chinese population. J Dermatol 41:353-354.

Zaraa I, Kerkeni N, Ishak F, Zribi H, El Euch D, Mokni M and Osman AB (2011) Spectrum of autoimmune blistering dermatoses in Tunisia: an 11-year study and a review of the literature. Int J Dermatol 50:939-944.

Zeoti DM, Figueiredo JF, Chiossi MP and Roselino AM (2000) Serum cytokines in patients with Brazilian pemphigus foliaceus (fogo selvagem). Braz J Med Biol Res 33:1065-1068.

Zhang P and Lu Q (2018) Genetic and epigenetic influences on the loss of tolerance in autoimmunity. Cell Mol Immunol 15:575-585.

Zhang SY, Zhou XY, Zhou XL, Zhang Y, Deng Y, Liao F, Yang M, Xia XY, Zhou YH, Yin DD et al. (2019) Subtype-specific inherited predisposition to pemphigus in the Chinese population. Br J Dermatol 180:828-835.
Zhao M, Huang W, Zhang Q, Gao F, Wang L, Zhang G, Su Y, Xiao $\mathrm{R}$, Zhang J, Tang M et al. (2012) Aberrant epigenetic modifications in peripheral blood mononuclear cells from patients with pemphigus vulgaris. Br J Dermatol 167:523-531.

Zheng J, Ibrahim S, Petersen F and Yu X (2012) Meta-analysis reveals an association of PTPN22 C1858T with autoimmune diseases, which depends on the localization of the affected tissue. Genes Immun 13:641-652.

Zivanovic D, Bojic S, Medenica L, Andric Z and Popadic D (2016) Human leukocyte antigen class II (DRB1 and DQB1) alleles and haplotypes frequencies in patients with pemphigus vulgaris among the Serbian population. HLA 87:367-374.

\section{Internet Resources}

Ensembl, https://www.ensembl.org (accessed 11 March 2020)

LDlink, https://ldlink.nci.nih.gov (accessed 10 May 2019)

Online Mendelian Inheritance in Man (OMIM), https://omim.org (accessed 30 May 2019)

\section{Supplementary material}

The following online material is available for this article:

Table S1 - HLA class II associations for pemphigus vulgaris.

Table S2 - HLA class II associations for pemphigus foliaceus.

\section{Associate Editor: Roberto Giugliani}

License information: This is an open-access article distributed under the terms of the Creative Commons Attribution License (type CC-BY), which permits unrestricted use, distribution and reproduction in any medium, provided the original article is properly cited. 